\title{
ORÓGENO ARAÇUAÍ: SÍNTESE DO CONHECIMENTO 30 ANOS APÓS ALMEIDA 1977
}

\author{
Antônio Carlos Pedrosa-Soares ${ }^{1}$, Carlos Maurício Noce ${ }^{1}$, Fernando Flecha de Alkmim², \\ Luiz Carlos da Silva ${ }^{3}$, Marly Babinski ${ }^{4}$, Umberto Cordani ${ }^{4}$, Cristiane Castañeda ${ }^{1}$
}

\begin{abstract}
The Araçuaí Fold Belt was defined as the southeastern limit of the São Francisco Craton in the classical paper published by Fernando Flávio Marques de Almeida in 1977. This keystone of the Brazilian geologic literature catalyzed important discoveries, such as of Neoproterozoic ophiolites and a calc-alkaline magmatic arc, related to the Araçuaí Belt and paleotectonic correlations with its counterpart located in Africa (the West Congo Belt), that provided solid basis to define the Araçuaí-West-Congo Orogen by the end of the $1990^{\text {th }}$ decade. After the opening of the Atlantic Ocean in Cretaceous times, two thirds of the Araçuaí-West-Congo Orogen remained in the Brazil side, including records of the continental rift and passive margin phases of the precursor basin, all ophiolite slivers and the whole orogenic magmatism formed from the pre-collisional to post-collisional stages. Thus, the name Araçuaí Orogen has been applied to the Neoproterozoic-Cambrian orogenic region that extends from the southeastern edge of the São Francisco Craton to the Atlantic coastline and is roughly limited between the $15^{\circ}$ and $21^{\circ} \mathrm{S}$ parallels. After 30 years of systematic geological mapping together with geochemical and geochronological studies published by many authors, all evolutionary stages of the Araçuaí Orogen can be reasonably interpreted. Despite the regional metamorfism and deformation, the following descriptions generally refer to protoliths. All mentioned ages were obtained by U-Pb method on zircon. The Macaúbas Group records rift, passive margin and oceanic environments of the precursor basin of the Araçuaí Orogen. From the base to the top and from proximal to distal units, this group comprises the pre-glacial Duas Barras and Rio Peixe Bravo formations, and the glaciogenic Serra do Catuni, Nova Aurora and Lower Chapada Acauã formations, related to continental rift and transitional stages, and the diamictitefree Upper Chapada Acauã and Ribeirão da Folha formations, representing passive margin and oceanic environments. Dates of detrital zircon grains from Duas Barras sandstones and Serra do Catuni diamictites suggest a maximum sedimentation age around 900 Ma for the lower Macaúbas Group, in agreement with ages yielded by the Pedro Lessa mafic dikes $(906 \pm 2 \mathrm{Ma})$ and anorogenic granites of Salto da Divisa $(875 \pm$ $9 \mathrm{Ma}$ ). The thick diamictite-bearing marine successions with sand-rich turbidites, diamictitic iron formation, mafic volcanic rocks and pelites (Nova Aurora and Lower Chapada Acauã formations) were deposited from the rift to transitional stages. The Upper Chapada Acauã Formation consists of a sand-pelite shelf succession, deposited after $c a .864 \mathrm{Ma}$ ago in the proximal passive margin. The Ribeirão da Folha Formation mainly consists of sand-pelite turbidites, pelagic pelites, sulfide-bearing cherts and banded iron formations, representing distal passive margin to oceanic sedimentation. Gabbro and dolerite with plagiogranite veins dated at $c a .660 \mathrm{Ma}$, and ultramafic rocks form tectonic slices of oceanic lithosphere thrust onto packages of the Ribeirão da Folha Formation. The pre-collisional, calc-alkaline, continental magmatic arc (G1 Suite, 630-585 Ma) consists of tonalites and granodiorites, with minor diorite and gabbro. A volcano-sedimentary succession of this magmatic arc includes pyroclastic and volcaniclastic rocks of dacitic composition dated at $c a .585 \mathrm{Ma}$, ascribed to the Palmital do Sul and Tumiritinga formations (Rio Doce Group), deposited from intra-arc to fore-arc settings. Detrital zircon geochronology suggests that the São Tomé wackes (Rio Doce Group) represent intra-arc to back-arc sedimentation after ca. 594 Ma ago. The Salinas Formation, a conglomerate-wacke-pelite association located to northwest of the magmatic arc, represents synorogenic sedimentation younger than $c a .588 \mathrm{Ma}$. A huge zone of syn-collisional S-type granites (G2 Suite, 582-560 $\mathrm{Ma}$ ) occurs to the east and north of the pre-collisional magmatic arc, northward of latitude $20^{\circ} \mathrm{S}$. Partial melting of G2 granites originated peraluminous leucogranites (G3 Suite) from the late- to post-collisional stages. A set of late structures, and the post-collisional intrusions of the S-type G4 Suite (535-500 Ma) and I-type G5 Suite (520-490 Ma) are related to the gravitational collapse of the orogen. The location of the magmatic arc, roughly parallel to the zone with ophiolite slivers, from the $17^{\circ} 30^{\prime} \mathrm{S}$ latitude southwards suggests that oceanic crust only developed along the southern segment of the precursor basin of the AraçuaíWest-Congo Orogen. This basin was carved, like a large gulf partially floored by oceanic crust, into the São Francisco-Congo Paleocontinent, but paleogeographic reconstructions show that the Bahia-Gabon cratonic bridge (located to the north of the Araçuaí Orogen) subsisted since at least $1 \mathrm{Ga}$ until the Atlantic opening. This uncommon geotectonic scenario inspired the concept of confined orogen, quoted as a new type of collisional orogen in the international literature, and the appealing nutcracker tectonic model to explain the Araçuaí-West-Congo Orogen evolution.
\end{abstract}

Palavras-chave: Faixa Araçuaí, Orógeno Araçuaí, Província Mantiqueira, Brasiliano

\section{INTRODUÇÃO}

Este artigo apresenta uma síntese do conhecimento sobre o Orógeno Araçuaí, com ênfase no significado das unidades neoproterozóicas e cambrianas para a caracterização de componentes geotectônicos e estágios evolutivos (Fig. 1). Os componentes geotectônicos são representados por processos e produtos (i.e., conjuntos de rochas) originados durante estágios evolutivos diversos, desde as bacias precursoras ao edifício

1. CPMTC-IGC-UFMG, Campus Pampulha, 31270-901 Belo Horizonte, MG; pedrosa@pesquisador.cnpq.br 2. DEGEO-UFOP, Campus do Cruzeiro, Ouro Preto, MG

3. CPRM-Serviço Geológico do Brasil, Brasília, DF

4. IG-USP, Cidade Universitária, São Paulo, SP 


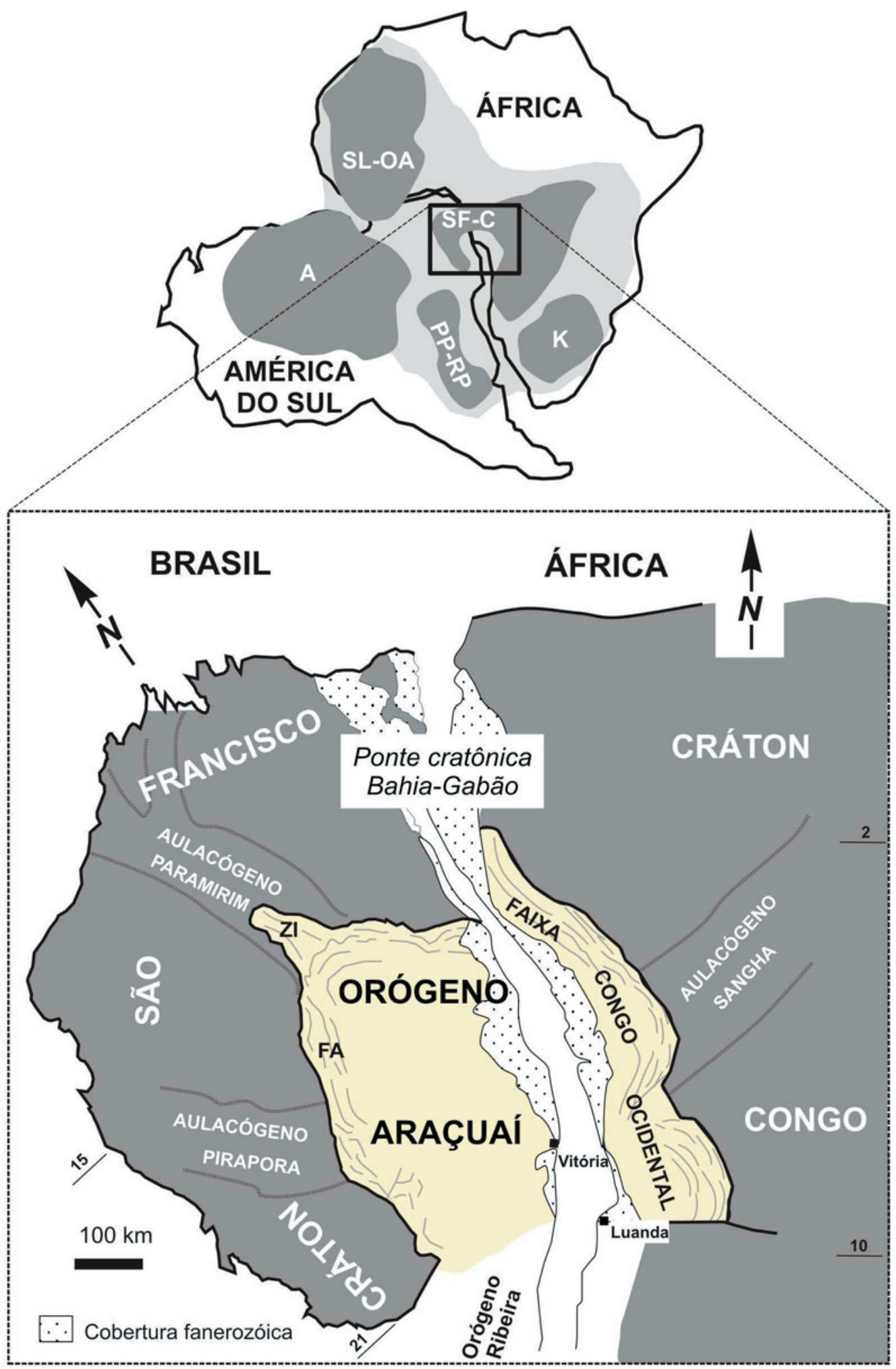

Figura 1. O Orógeno Araçuai na região central do Paleocontinente Gondwana (modificado de Alkmim et al. 2006). FA, traços estruturais da Faixa de Dobramentos Araçuaí (sensu Almeida 1977); ZI, zona de interferência do Orógeno Araçuaí com o Aulacógeno do Paramirim. Crátons: A, Amazônico; K, Kalahari; PP-RP, Paraná-

Paranapanema-Rio de la Plata; SF-C, São Francisco-Congo; SL-OA, São Luís-Oeste Africano.

resultante da orogenia. Como exemplo de componentes geotectônicos tem-se o magmatismo bimodal originado em rifte continental, restos ofiolíticos indicadores de espalhamento oceânico, arco magmático relacionado a subducção e granitos tipo $\mathrm{S}$ originados durante a colisão. Os principais estágios evolutivos da bacia precursora são: i) rifte continental (associação ruditoarenito-pelito com magmatismo bimodal tipo A), ii) 
margem continental passiva (associação arenito-pelitocarbonato, turbiditos areno-pelíticos, magmatismo ausente), e iii) oceânico (rochas magmáticas ofiolíticas, sedimentação pelágica e químico-exalativa). Os estágios orogênicos são: i) pré-colisional (subducção de litosfera oceânica ativa, geração de arco magmático cálcio-alcalino), ii) sin-colisional (interação direta entre as partes em colisão, clímax da tectônica tangencial ou "horizontal", espessamento crustal, fusão parcial e geração de magma tipo S), iii) tardi-colisional (tectônica tangencial cessante, escapes laterais, geração de granito S por fusão parcial sob descompressão adiabática), e iv) pós-colisional (colapso gravitacional, plutonismo tipo I e A2).

O artigo no qual o Professor Fernando Flávio Marques de Almeida definiu a Faixa de Dobramentos Araçuaí, publicado em 1977, se tornou um dos marcos da literatura geológica brasileira. Este artigo, cujo objetivo fundamental foi rever os limites do Cráton do São Francisco e estabelecer sua definição, deixou inestimável contribuição para a geologia do sudeste brasileiro ao caracterizar como faixa orogênica brasiliana uma vasta área que, anteriormente, se incluía na região cratônica (Almeida 1977; ver também Alkmim et al. 1993). Decorridas três décadas desde Almeida (1977), muitos dos desafios científicos catalisados pela definição da Faixa Araçuaí ganharam respostas sólidas, alicerçadas em mapeamento geológico sistemático e dados laboratoriais, publicados por muitos autores.

Entretanto, na conceituação original da Faixa Araçuaí seus limites meridional e oriental ficaram indefinidos. Por sua vez, a Faixa Ribeira foi caracterizada com forte conotação tectono-metamórfica ("feixe de transcorrências de direção NE, impresso em rochas de alto grau metamórfico"), e seu limite setentrional foi deixado em aberto (Hasui et al. 1975). Estas indefinições de fronteiras resultaram em interpretações as mais variadas para as aplicações dos nomes Araçuaí e Ribeira, em particular quando se tratava da grande área dominada por rochas graníticas e metamórficas de alto grau, que se estende pelo Espírito Santo, leste de Minas Gerais e sul da Bahia (e.g., Inda \& Barbosa 1978, Siga-Júnior et al. 1982, Almeida \& Hasui 1984, Schobbenhaus et al. 1984, Siga-Júnior 1986, Silva et al. 1987). Dentre várias tentativas de esclarecer a questão (Araçuaí ou Ribeira?), uma delas fundamentou-se no conceito de orógeno e buscou reinterpretar estas faixas em termos da "Orogenia Rio Doce" (Campos-Neto \& Figueiredo 1995).

A partir de meados da década de 1990 ficaram disponíveis os resultados de grandes projetos de mapeamento geológico sistemático na escala 1:100.000, elaborados sobre bases conceituais modernas, que cobrem a maior parte da região aqui focalizada. Paralelamente, surgiram muitos outros dados essenciais à interpretação geotectônica, tais como seções estruturais regionais, dados litoquímicos e estudos isotópicos pelos métodos $\mathrm{U}-\mathrm{Pb}, \mathrm{Sm}-\mathrm{Nd}$ e $\mathrm{Pb}-\mathrm{Pb}$. Este grande acervo de dados sustentou a marcante evolução do conhecimento geológico sobre a região e possibilitou a definição do Orógeno Araçuaí.

O Orógeno Araçuaí é uma escola natural de geotectônica, pois seus afloramentos ensinam que os componentes geotectônicos e estágios evolutivos previstos pela Teoria da Tectônica Global, se adequadamente abordados, podem ser descobertos, ordenados no tempo e representados em modelos; e, por isto, lançam novos desafios para investigação científica e prospecção mineral.

\section{DEFINIÇÃO DO ORÓGENO ARAÇUAÍ}

O trabalho pioneiro de Almeida (1977) lançou questões que impulsionaram o ritmo e balizaram o rumo das investigações geotectônicas sobre a Faixa Araçuaí. Duas destas questões, cujas respostas são fundamentais para interpretação geotectônica à luz da Teoria da Tectônica Global, são adiante referidas juntamente com as descobertas delas decorrentes:

1. Se a Faixa Araçuaí foi definida como geossinclinal alpinótipo, onde estariam seus ofiolitos? A iniciativa que levou à descoberta de remanescentes de litosfera oceânica neoproterozóica na Faixa Araçuaí se inspirou nesta questão e ocorreu no final da década de 1980 (Pedrosa-Soares et al. 1990, 1992).

2. Se existem ofiolitos na Faixa Araçuaí, qual seria o arco magmático cálcio-alcalino relacionado ao consumo desta litosfera oceânica? $\mathrm{O}$ melhor candidato a arco magmático relacionado ao consumo da litosfera oceânica da Faixa Araçuaí seria o batólito tonalítico Galiléia (Barbosa et al. 1964). De fato, a primeira caracterização geoquímica e isotópica detalhada deste batólito tonalítico evidenciou sua origem em arco magmático continental, edificado em torno de 594 Ma (Nalini 1997). A vinculação da gênese deste arco magmático com o consumo da litosfera oceânica da Faixa Araçuaí foi, então, uma conseqüência inevitável (Pedrosa-Soares et al. 1998).

Com base nestas descobertas, na correlação entre as faixas Araçuaí e Congo Ocidental (Brito-Neves \& Cordani 1991, Trompette 1994) e na relação cronoespacial dos conceitos de orógeno e cráton definiu-se o Orógeno Araçuaí-Congo Ocidental (Araçuaí-WestCongo Orogen) para referir o conjunto orogênico neoproterozóico-cambriano contido na grande reentrância delineada pelos crátons do São Francisco e Congo, cujo limite meridional no Brasil seria balizado pela extremidade sul do Cráton do São Francisco na altura do paralelo $21^{\circ} \mathrm{S}$ (Pedrosa-Soares \& Noce 1998, Pedrosa-Soares \& Wiedemann-Leonardos 2000, Pedrosa-Soares et al. 2001). Nesta conceituação, o Orógeno Araçuaí-Congo Ocidental é identificado por um conjunto de componentes geotectônicos que caracterizam um orógeno colisional sucessor de um orógeno acrescionário de margem continental ativa, tais como depósitos de margem passiva, lascas ofiolíticas, zona de sutura, arco magmático, granitos sin-colisionais e plutonismo pós-colisional. 
Mas, o Orógeno Araçuaí-Congo Ocidental tem uma característica singular que é seu confinamento à reentrância (a cratonic embayment) limitada pelos crátons do São Francisco e Congo (Pedrosa-Soares et al. 2001). A natureza confinada deste orógeno decorre do fato de que os crátons São Francisco e Congo permaneceram parcialmente ligados, pelo menos desde a tafrogênese toniana (mas, muito provavelmente desde $2 \mathrm{Ga}$ ) até a abertura do Atlântico Sul, no Cretáceo, por meio da ponte continental que unia as regiões de Bahia e Gabão (e.g., Torquato \& Cordani 1981, Porada 1989, D'Agrella et al. 1990, 2004, Ledru et al. 1994, Trompette 1994, Brito-Neves et al. 1999). Desta forma, a bacia precursora deste orógeno seria um golfo parcialmente oceanizado (do tipo inland sea-basin) e articulado com aulacógenos (Pedrosa-Soares et al. 1998, 2001, 2008, Alkmim et al. 2006), que desembocaria no Oceano Adamastor (Cordani et al. 2003). O orógeno resultante se caracteriza, então, como confinado e seu mecanismo de evolução tectônica seria similar ao fechamento de um quebra-nozes, mas catalisado por colisões à distância (Alkmim et al. 2003, 2006, 2007). O conceito de orógeno confinado (Pedrosa-Soares et al. 2001, 2003) foi adotado, como um novo tipo de edifício colisional, na tríplice classificação (intercratônico, intracratônico, confinado) de Rogers \& Santosh (2004).

Os aulacógenos Pirapora, Paramirim e Sangha (Fig. 1) teriam cumprido importantes funções, tanto ao facilitar o alargamento e oceanização do setor meridional da bacia precursora do Orógeno AraçuaíCongo Ocidental, quanto ao acomodar a deformação brasiliana no interior da região cratônica (PedrosaSoares et al. 1992, Alkmim et al. 2003, 2006, 2007).

O Orógeno Araçuaí-Congo Ocidental engloba, no Brasil, a Faixa de Dobramentos Araçuaí (sensu Almeida 1977) e o setor dominado por rochas graníticas e de alto grau metamórfico que se estende até o litoral Atlântico, entre os paralelos $15^{\circ}$ e $21^{\circ} \mathrm{S}$; e, na África, a Faixa Congo Ocidental que é marginal ao Cráton do Congo entre os paralelos $2^{\circ}$ e $10^{\circ} \mathrm{S}$ (Fig. 1). Em decorrência da abertura do Atlântico Sul, no Cretáceo, a contraparte Araçuaí herdou dois terços do Orógeno Araçuaí-Congo Ocidental, ficando com unidades do rifte continental, a margem passiva ocidental com restos ofiolíticos, a zona de sutura, o arco magmático e bacias relacionadas, e todo o conjunto magmático sin- a póscolisional. A Faixa Congo Ocidental guardou espessa pilha vulcano-sedimentar da fase rifte continental, a margem passiva oriental e uma bacia molássica. De fato, as contrapartes do Orógeno Araçuaí-Congo Ocidental são diferentes, embora complementares (PedrosaSoares et al. 2008).

Como a contraparte brasileira do Orógeno AraçuaíCongo Ocidental contém todos os componentes geotectônicos necessários para se caracterizar um orógeno colisional, e o presente artigo é nela focado, simplifica-se a denominação para Orógeno Araçuaí. Este orógeno representa o segmento setentrional da Província Mantiqueira (Heilbron et al. 2004).

\section{UNIDADES ESTRATIGRÁFICAS, COMPONENTES GEOTECTÔNICOS E ESTÁGIOS EVOLUTIVOS}

Apresenta-se uma síntese sobre as unidades estratigráficas neoproterozóicas e cambrianas do Orógeno Araçuaí, relacionando-as a componentes geotectônicos e estágios evolutivos. O embasamento e a evolução tectônica do orógeno são abordados por Noce et al. (2007) e Alkmim et al. (2007), neste fascículo de Geonomos. As descrições adiante geralmente se referem a protolitos, a despeito do metamorfismo regional que varia da fácies xisto verde baixo a granulito.

\section{A Bacia Precursora do Orógeno Araçuaí}

$\mathrm{O}$ estágio de rifte continental da bacia precursora está bem registrado no domínio externo (proximal) do Orógeno Araçuaí, particularmente na região a norte de Diamantina, onde as unidades proximais do Grupo Macaúbas ocorrem em larga extensão, e na área de ocorrência da Suíte Salto da Divisa (Fig. 2, 3, 4 e 5). Para o Grupo Macaúbas adota-se a estratigrafia regional sintetizada por Noce et al. (1997) e cartograficamente revista por CPRM-CODEMIG (2003).

O magmatismo da fase rifte é representado pelos diques máficos da Suíte Pedro Lessa $(906 \pm 2 \mathrm{Ma}$, U-Pb TIMS, zircão e baddeleyita; Machado et al. 1989), granitos anorogênicos da Suíte Salto da Divisa ( $875 \pm 9$ Ma, U-Pb SHRIMP, zircão; Silva et al. 2002, 2007) e pelos xistos verdes basálticos do Membro Rio Preto da Formação Chapada Acauã (Gradim et al. 2005, Babinski et al. 2005, Martins 2006). Os corpos metamáfico-ultramáficos acamadados de Ipanema também seriam registros do magmatismo do estágio rifte (Angeli et al. 2004). As idades das suítes Pedro Lessa e Salto da Divisa definem o início do estágio de rifte continental da bacia precursora do Orógeno Araçuaí, entre ca. 906 e 875 Ma. O vulcanismo Rio Preto representaria episódio tardio em relação a estas suítes, como se refere adiante.

A Suíte Salto da Divisa consiste de granitos alcalinos com autólitos gabróicos, portadores de fluorita, que foram envolvidos na deformação regional, mas apresentam porções com textura magmática bem preservada (Paixão \& Perrella 2004, Sampaio et al. 2004, Silva et al. 2007). Os corpos desta suíte intrudem o embasamento do extremo nordeste do Orógeno Araçuaí e seu contato com o Complexo Jequitinhonha é uma marcante zona de cisalhamento transcorrente (Fig. 2).

A sedimentação de fases diversas do rifte continental está representada nas formações Duas Barras, Rio Peixe Bravo, Serra do Catuni, Nova Aurora e unidade inferior da Formação Chapada Acauã, do Grupo Macaúbas (Noce et al. 1997; a unidade carbonática denominada Formação Domingas passou a ser correlacionada ao Supergrupo Espinhaço após Santos et al. 2004). As formações Duas Barras e Rio Peixe Bravo incluem arenitos, pelitos e raros conglomerados que registram sedimentação fluvial a marinha, sem vestígios de 


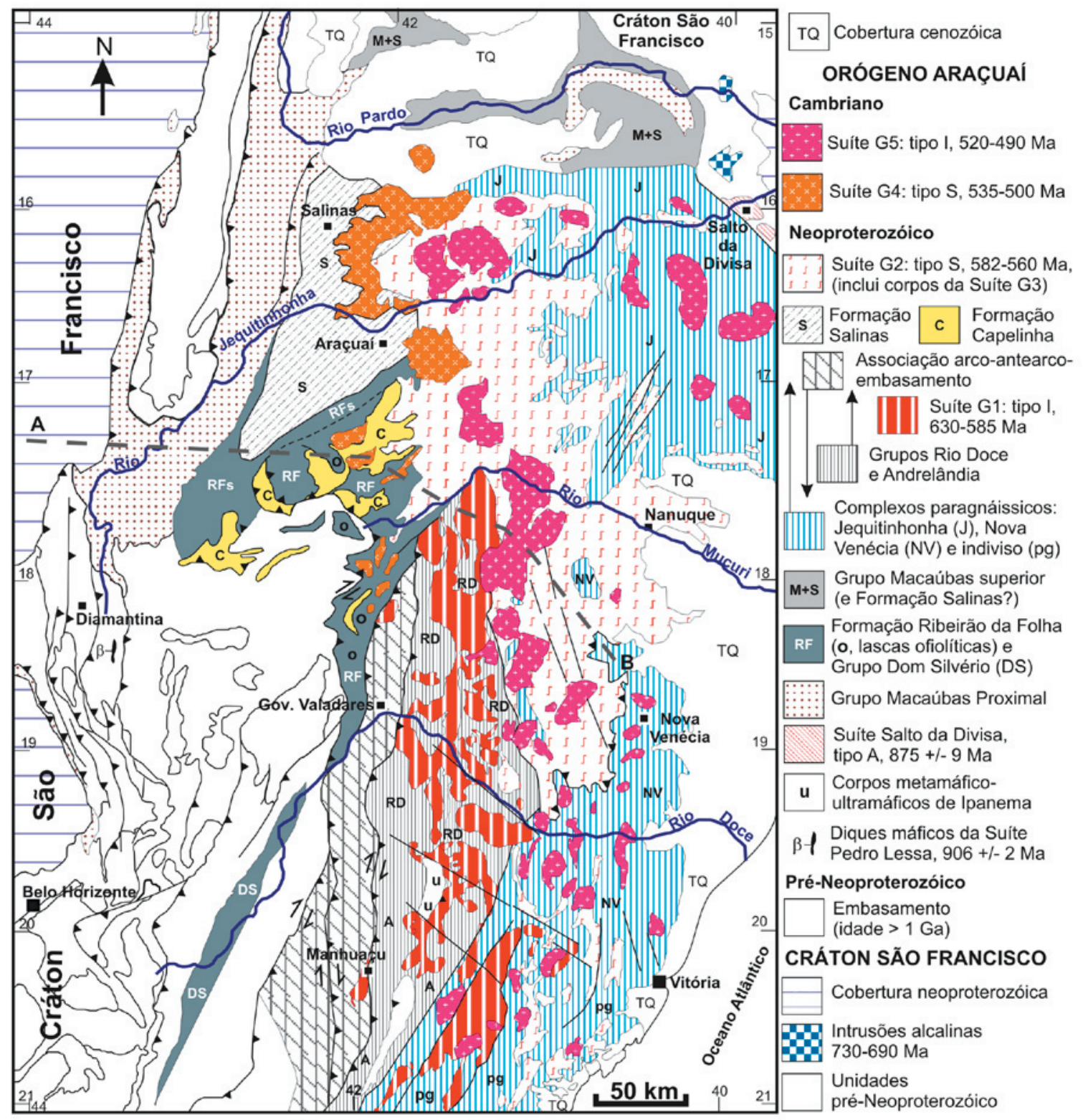

Figura 2. Mapa geológico do Orógeno Araçuaí.

glaciação (Noce et al. 1997, Grossi-Sad et al. 1997, Martins 2006). A idade máxima de sedimentação é $900 \pm 21 \mathrm{Ma}$, como indica a datação de grãos de zircão detrítico extraídos de arenito Duas Barras (UPb SHRIMP, Babinski et al. 2007). Esta idade limita também a época do início da deposição do Grupo Macaúbas.

Unidades glaciogênicas também se depositaram durante a fase rifte da bacia Macaúbas (e.g., Karfunkel et al. 1985, Karfunkel \& Hoppe 1988, Mourão \& Pedrosa-Soares 1992, Pedrosa-Soares et al. 1992, 1998, Grossi-Sad et al. 1997, Noce et al. 1997, Uhlein et al. 1998, 1999, 2007, Martins-Neto et al. 2001, MartinsNeto \& Hercos 2002). A mais antiga delas é a Formação Serra do Catuni, constituída por diamictitos maciços com intercalações esparsas de arenitos e pelitos (que, em alguns casos, seriam varvitos), representantes de sedimentação glácio-terrestre a glácio-marinha (Fig.
3 e 4). Dados U-Pb SHRIMP de zircões detríticos balizam a idade máxima de deposição da Formação Serra do Catuni em $933 \pm 9$ Ma (Babinski et al. 2007). Este dado, juntamente com o da Formação Duas Barras (acima referido) e outras idades de zircões detríticos do Grupo Macaúbas (Pedrosa-Soares et al. 2000) sugerem fontes sedimentares localizadas em ombreiras e horsts que expuseram à erosão a espessa pilha magmática do rifte que se situa na Faixa Congo Ocidental (Tack et al. 2001, Pedrosa-Soares et al. 2008).

A sedimentação glácio-marinha se torna mais espessa e extensa nas formações Nova Aurora e Chapada Acauã (Fig. 3 e 4). A Formação Nova Aurora consiste predominantemente de diamictitos (fluxos de detritos) e turbiditos arenosos, com importantes intercalações de formações ferríferas diamictíticas do tipo Rapitan (Viveiros et al. 1978, Uhlein 1991, Grossi-Sad et al. 1997, Noce et al. 1997). A unidade inferior da Formação 


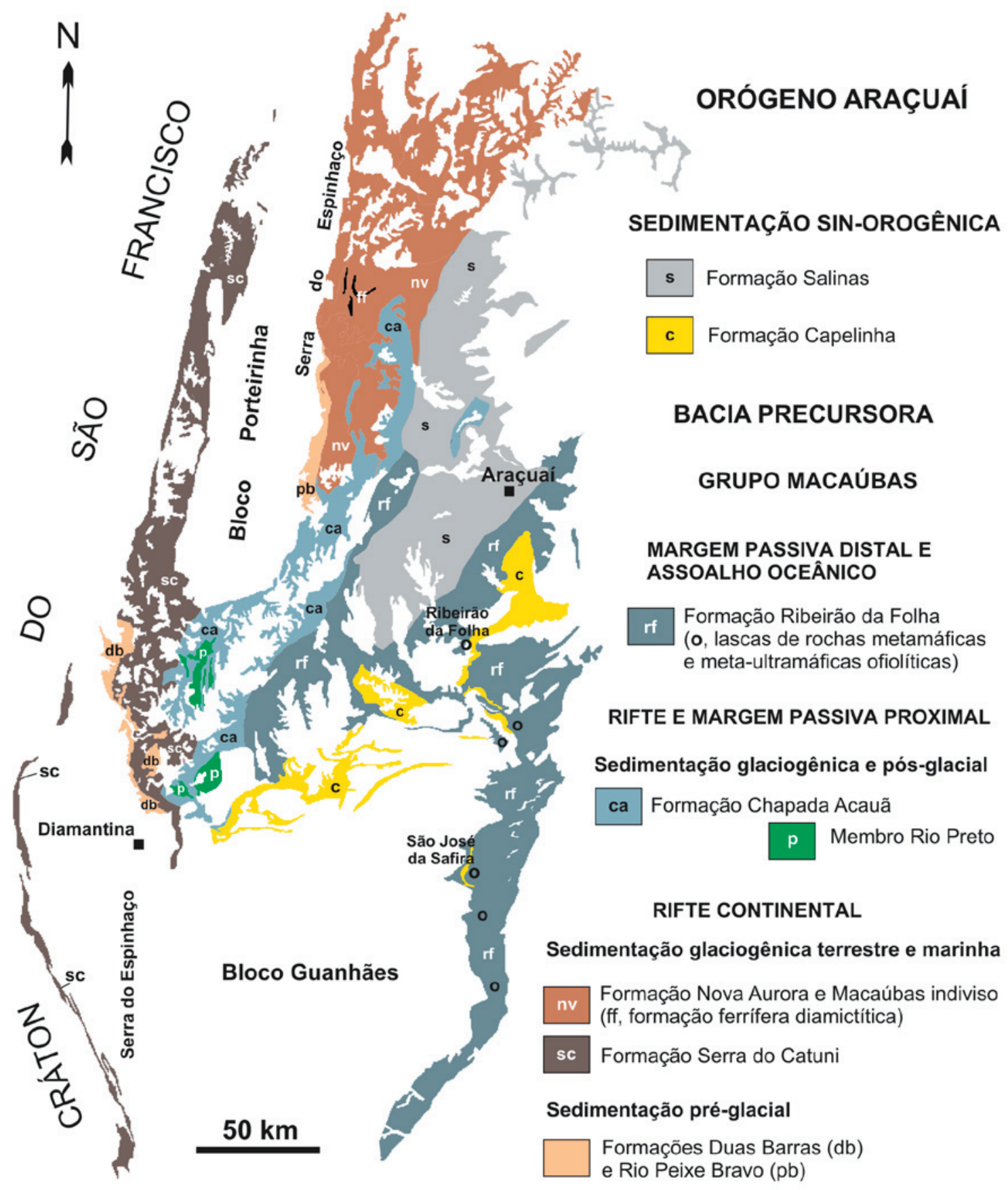

Figura 3. Distribuição de unidades da bacia precursora do Grupo Macaúbas e de formações sin-orogênicas do Orógeno Araçuaí (modificado de CPRM-CODEMIG 2003).

Chapada Acauã (Membro Mato Grande) é uma sucessão cíclica de intercalações de diamictitos, turbiditos arenosos e pelitos, com pelo menos uma espessa lente de calcário dolomítico no topo (Mourão \& Pedrosa-Soares 1992, Pedrosa-Soares et al. 1992, Grossi-Sad et al. 1997, Noce et al. 1997, Pedrosa-Soares \& Grossi-Sad 1997, Martins 2006). Xistos verdes, intercalados em parte da pilha diamictítica da Formação Chapada Acauã (Membro Rio Preto), preservam estrutura almofadada e outras evidências de derrames submarinos, cujas assinaturas geoquímica e isotópica $\mathrm{Sm}-\mathrm{Nd}$ indicam basaltos transicionais como protolitos (Uhlein 1991, CPRM-CODEMIG 2003, Gradim et al. 2005). As diversas populações de zircões herdados, extraídas dos xistos verdes, evidenciam que o magma basáltico atravessou crosta continental e que o vulcanismo é mais jovem que 1,1 Ga (Babinski et al. 2005). Este fato e as assinaturas geoquímica e isotópica sugerem que o vulcanismo Rio Preto ocorreu na fase tardia do rifte Macaúbas, quando a crosta continental já se encontrava muito estirada (Gradim et al. 2005).

$\mathrm{O}$ estágio de abertura da bacia precursora, que se 
Suíte G4: granito tipo $S$, pós-colisional, ca. 535 - $500 \mathrm{Ma}$
Suite G5: plutonismo tipo I,

pós-colisional, ca. 520 - $490 \mathrm{Ma}$

Suíte G3: cordierita-granada leucogranito, fusões

autóctones e parautóctones, ca. $545-520 \mathrm{Ma}$

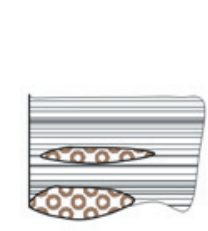

Formação Salinas: marinha, sin-orogênica, idade $<588+/-24 \mathrm{Ma}$

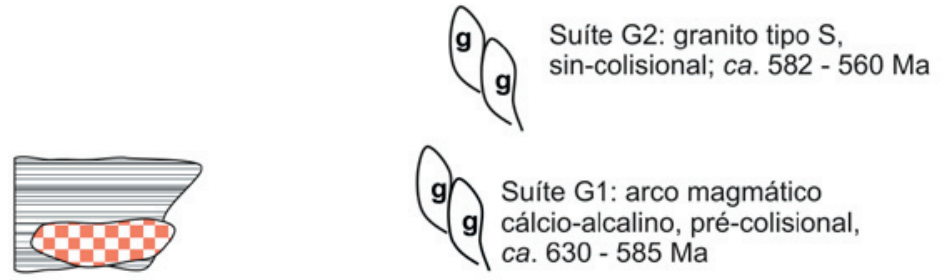

Grupo Rio Doce Inferior e Complexo Nova Venécia: bacias diretamente associadas ao arco magmático (idades no texto)

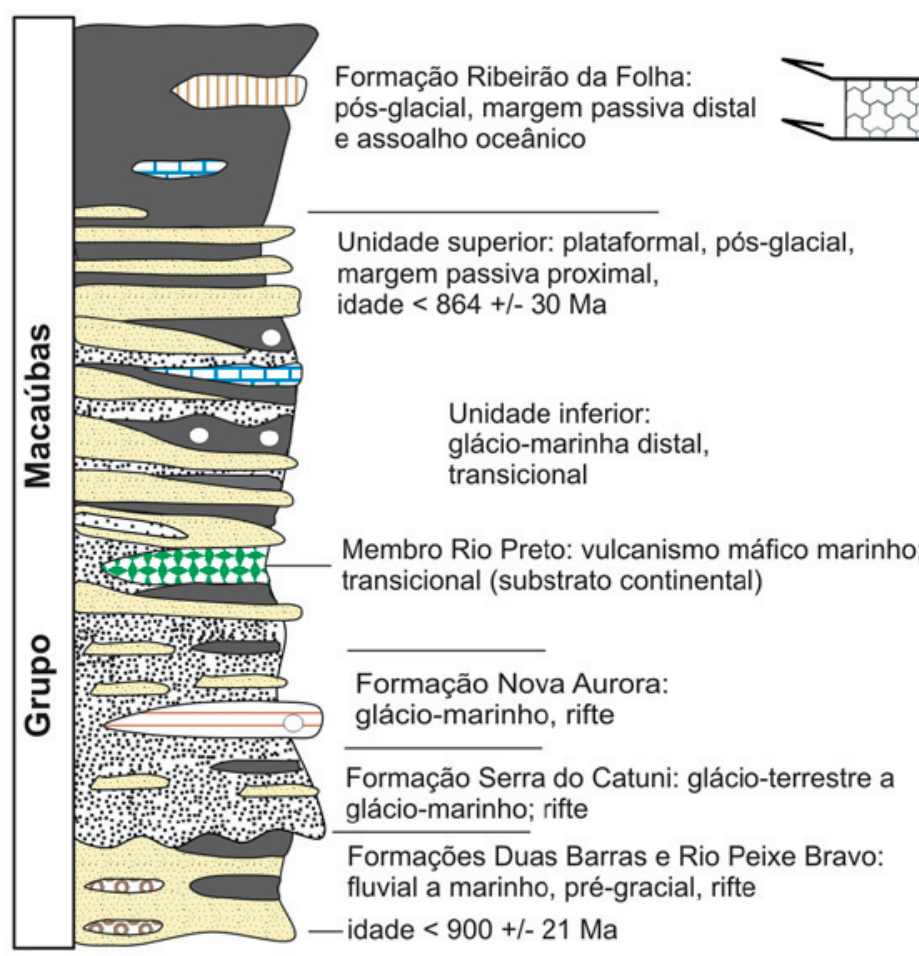

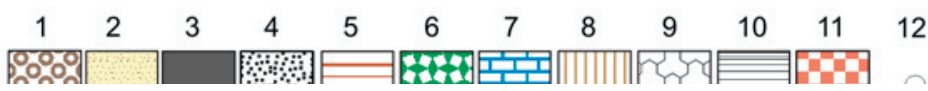

Figura 4. Coluna estratigráfica esquemática do Orógeno Araçuai (modificada de Pedrosa-Soares et al. 2008). 1, conglomerados; 2, arenitos; 3, pelitos; 4, diamictitos; 5, formação ferrifera diamictítica; 6 , basalto transicional; 7, calcário dolomítico; 8, sedimentos exalativos (chert sulfetado, sulfeto maciço, formações ferríferas e outros);

9, rochas máficas (com veios de plagiogranito) e ultramáficas oceânicas; 10, wackes e pelitos; 11, rochas piroclásticas e vulcanoclásticas dacíticas; 12, seixos e blocos pingados.

seguiu ao rifte continental, levou à deposição da pilha sedimentar da margem continental passiva e formação de litosfera oceânica, como indicam os registros litológicos da unidade superior da Formação Chapada Acauã, Formação Ribeirão da Folha, e lascas tectônicas de rochas máficas e ultramáficas ofiolíticas (PedrosaSoares et al. 1992, 1998, 2001, 2008, Pedrosa-Soares
1995, 1997, Grossi-Sad et al. 1997, Noce et al. 1997, Pedrosa-Soares \& Grossi-Sad 1997, Uhlein et al. 1998, Aracema et al. 2000, Suita et al. 2004, Queiroga et al. 2006, 2007). Este estágio transcorreu sem influência glacial, uma vez que as unidades que o representam são livres de diamictito e de qualquer outro indício de glaciação (Fig. 2, 3, 4 e 5). A unidade superior da 
Formação Chapada Acauã consiste de intercalações de arenito e pelito, representantes da sedimentação plataformal no setor proximal da margem passiva. A idade máxima de deposição é indicada por zircão detrítico datado em $864 \pm 30 \mathrm{Ma}$ (U-Pb SHRIMP, Pedrosa-Soares et al. 2000). Este valor é similar, na margem de erro, à idade dos granitos anorogênicos de Salto da Divisa, mais uma vez indicando soerguimento e erosão de blocos na bacia Macaúbas antes do estágio de margem passiva.

A Formação Ribeirão da Folha contém depósitos da margem passiva distal e da sedimentação oceânica. $\mathrm{O}$ setor ocidental da margem passiva distal é representado pelos turbiditos areno-pelíticos (quartzo-mica xistos bandados e micaxistos peraluminosos) com intercalações de pelitos carbonosos (grafita xistos), margas (rochas calcissilicáticas a quartzo, plagioclásio, anfibólio, epidoto, granada cálcica e/ou clinopiroxênio) e raro calcário que compõem a parte exclusivamente sedimentar da Formação Ribeirão da Folha (RFs na Figura 2). O setor oriental da Formação Ribeirão da Folha (RF na Figura 2) inclui sucessão vulcanosedimentar de assoalho oceânico, caracterizada por pelitos pelágicos (micaxistos peraluminosos ricos em estaurolita, granada, cianita e/ou sillimanita, e cianitagrafita xistos), cherts sulfetados com intercalações de sulfetos maciços e diopsidito sulfetado (uma rocha rara que sugere depósito de conduto exalativo), formações ferríferas bandadas dos tipos óxido, silicato e sulfeto, e raro orto-anfibolito de granulação fina (cuja assinatura geoquímica e epsilon $\mathrm{Nd}$ em torno de +4 evidenciam basalto oceânico como protolito). Desta forma, a parte distal da Formação Ribeirão da Folha representa a seção superior (camada 1), sedimentar, incluindo parte da seção vulcânica (camada 2), de uma coluna ofiolítica (Suita et al. 2004).

As rochas ofiolíticas que testemunham seções inferiores de litosfera oceânica são orto-anfibolitos de granulação média e grossa (dolerito, gabro) e rochas meta-ultramáficas, que ocorrem em lascas tectônicas de empurrão alojadas nas formações Ribeirão da Folha e Capelinha (Fig. 5). Os atributos geoquímicos das rochas máficas e ultramáficas localizadas nas proximidades de Ribeirão da Folha e São José da Safira (Fig. 3) revelam assinatura de assoalho oceânico e afinidade com outros complexos ofiolíticos neoproterozóicos. Os dados isotópicos $\mathrm{Sm}-\mathrm{Nd}$, tais como epsilon $\mathrm{Nd}$ variável entre +3 e +7 , e idades modelo e isocrônica, corroboram a assinatura geoquímica das rochas máficas e ultramáficas, e indicam formação da litosfera oceânica no Neoproterozóico (Pedrosa-Soares et al. 1992, 1998, 2001, 2008, Aracema et al. 2000). Ortoanfibolitos bandados (dolerito a gabro) hospedam veios de plagiogranito que, recentemente, foram datados em $660 \pm 29 \mathrm{Ma}$ (zircão, U-Pb LA-ICPMS; Queiroga et al. 2007). Esta idade indica a época da cristalização magmática do ofiolito de Ribeirão da Folha.

A parte distal (RF, Fig. 3) da Formação Ribeirão Folha tem sido correlacionada ao Grupo Dom Silvério, em decorrência da similaridade de associações litológicas e provável continuidade física no terreno (Pinto et al. 1997, 2001, Cunningham et al. 1998, Pedrosa-Soares et al. 2001, Peres et al. 2004).

$\mathrm{Na}$ região setentrional do Orógeno Araçuaí ocorre extensa unidade areno-pelítica $(\mathrm{M}+\mathrm{S}$ na Figura 2) correlacionável, pelo menos em parte, ao Grupo Macaúbas (Almeida et al. 1978, Pedrosa-Soares \& Wiedemann-Leonardos 2000, Pedrosa-Soares et al. 1992, 2001, Sampaio et al. 2004), mas que em outros trabalhos foi atribuída ao Supergrupo Espinhaço (Barbosa \& Dominguez 1996). Considerase, entretanto, que nesta região se encontre uma possível associação espacial de depósitos de margem passiva (Grupo Macaúbas Superior, pós-glacial) com depósitos sin-orogênicos (Formação Salinas), pois as rochas metapelíticas (xistos micáceos com granada, estaurolita, cianita e/ou sillimanita) destas unidades são facilmente confundidas no terreno, em decorrência do metamorfismo e deformação.

Os complexos Jequitinhonha e paragnáissico indiviso são, também, candidatos a conter depósitos de margem passiva espacialmente associados a pilhas sedimentares provenientes de arco magmático (Pedrosa-Soares \& Wiedemann-Leonardos 2000, Sampaio et al. 2004, Heilbron et al. 2004, PedrosaSoares et al. 2008). O Complexo Jequitinhonha é constituído de paragnaisses aluminosos a peraluminosos (kinzigíticos) com intercalações de quartzito, grafita gnaisse e rochas calcissilicáticas, incluindo as maiores jazidas de grafita lamelar do Brasil (e.g., Faria 1997, Daconti 2004). O complexo paragnáissico indiviso que ocorre no setor sudeste do Orógeno Araçuaí e se prolonga para o Orógeno Ribeira, onde é subdividido em unidades diversas, inclui paragnaisses com intercalações de mármores, anfibolitos, quartzitos e rochas calcissilicáticas (Heilbron et al. 2004).

\section{Componentes e Estágios Orogênicos}

No Orógeno Araçuaí são reconhecidos quatro estágios orogênicos denominados pré-colisional ( $c a$. 630 - $580 \mathrm{Ma}$ ), sin-colisional (ca. 580 - $560 \mathrm{Ma}$ ), tardicolisional ( ca. 560 - $530 \mathrm{Ma}$ ) e pós-colisional ( $c a .530$ - 490 Ma). Estes estágios são caracterizados com base nas relações estruturais (em particular, com a foliação regional), assinaturas geoquímicas e isotópicas, e idades $\mathrm{U}-\mathrm{Pb}$ das rochas que os representam (Pedrosa-Soares \& Wiedemann-Leonardos 2000, Pedrosa-Soares et al. 2001, 2008, Silva et al. 2005).

No estágio pré-colisional (acrescionário) foi edificado o arco magmático do Orógeno Araçuaí, representado pela Suíte G1 e rochas vulcânicas do Grupo Rio Doce (Fig. 2, 4 e 5). A Suíte G1 é constituída majoritariamente por tonalitos e granodioritos, com fácies e autólitos dioríticos e máficos, portadores de xenólitos de rochas metassedimentares. Os corpos G1 são batólitos e stocks que apresentam a foliação regional, muitas vezes milonítica, e outras estruturas impressas pela deformação sin-colisional, em quase toda sua 
extensão. Os dados litoquímicos e isotópicos (epsilon $\mathrm{Nd}$ entre -5 e -13, e idades-modelo $\mathrm{T}_{\mathrm{DM}}$ entre 1,2 e 2,2 $\mathrm{Ga}$ ) das rochas $\mathrm{G} 1$ evidenciam uma suíte cálcio-alcalina expandida que representa arco magmático de margem continental ativa, edificado entre $c a .630$ e $585 \mathrm{Ma}$, com assinatura híbrida e contribuição de magmas crustais predominante sobre magmas mantélicos (e.g., Nalini et al. 2000, 2005, Noce et al. 2000, 2006, Pedrosa-Soares \& Wiedemann-Leonardos 2000, Pedrosa-Soares et al. 2001, 2008, Pinto et al. 2001, Whittington et al. 2001, Campos et al. 2004, Martins et al. 2004, Silva et al. 2005, Horn 2006, Novo et al. 2007).

Rochas vulcânicas deste arco magmático foram recentemente caracterizadas em unidades inferiores do Grupo Rio Doce (Vieira 2007, Vieira et al. 2007). Na Formação Palmital do Sul, basal, ocorrem tufos piroclásticos com bombas vulcânicas esparsas. A Formação Tumiritinga contêm rochas vulcanoclásticas (tufos, cinzas). As rochas vulcânicas têm composição dacítica e assinatura geoquímica de arco vulcânico continental, com idades de cristalização magmática (zircão, U-Pb LA-ICPMS e TIMS) em torno de 585 Ma. Estas formações são interpretadas como depósitos de bacias intra-arco a ante-arco, preenchidas no estágio tardio de desenvolvimento do arco magmático. A Formação São Tomé, que recobre as unidades acima referidas, é composta por wackes e pelitos que têm contribuição sedimentar do arco magmático revelada por sua composição mineralógica, assinatura geoquímica e grãos detríticos de zircão com idades em torno de $595 \mathrm{Ma}$. Esta unidade teria se depositado na parte proximal da bacia retro-arco.

O setor distal da bacia retro-arco é representado pelos paragnaisses com intercalações de rochas calcissilicáticas do Complexo Nova Venécia (Noce et al. 2004, Pedrosa-Soares et al. 2006). Os protolitos destes paragnaisses são pelitos grauvaquianos, cuja assinatura geoquímica é indicadora de fontes sedimentares situadas em arco magmático (Pedrosa-Soares et al., em preparação). Os dados dos grãos detríticos de zircão mais jovens e menos discordantes, datados por Noce et al. (2004), sugerem idade máxima de sedimentação dos protolitos do Complexo Nova Venécia em $608 \pm$ $18 \mathrm{Ma}$ (Pedrosa-Soares et al. 2008).

A Formação Salinas, composta por wackes ("'arenito grauvaquiano"), pelitos e conglomerados, também mostra evidências marcantes de uma bacia que recebeu sedimentos provenientes do arco magmático do Orógeno Araçuaí (Lima et al. 2002). Por apresentar, na área-tipo, seções livres da deformação regional e com metamorfismo muito fraco, a Formação Salinas foi interpretada como tardi-orogênica por Lima et al. (2002). Entretanto, esta unidade passou a ser interpretada como registro de sedimentação sinorogênica (flysch) após os estudos tectônicos regionais de Santos et al. (2007; ver também Alkmim et al. 2007). Se considerados apenas os zircões mais jovens e com discordância menor que $10 \%$, dentre os dados apresentados por Lima et al. (2002), a idade máxima da
Formação Salinas é $588 \pm 24$ Ma (Pedrosa-Soares et al. 2008). Além disso, a assinatura geoquímica dos wackes Salinas revela proveniência de arco magmático e seus conglomerados contêm seixos de rochas vulcânicas com idades de cristalização magmática no intervalo da Suíte G1 (Pedrosa-Soares et al., em preparação).

O conjunto litológico informalmente denominado associação arco-antearco-embasamento compreende unidades de naturezas e idades diversas, que ainda carecem de melhor discriminação cartográfica e de dados laboratoriais. Esta associação inclui rochas do embasamento paleoproterozóico, prováveis remanescentes ofiolíticos neoproterozóicos, sucessões atribuídas aos grupos Andrelândia e Rio Doce, corpos tonalítico-granodioríticos da Suíte G1 e intrusões graníticas sin- a pós-colisionais. As rochas do embasamento são atribuídas aos complexos Juiz de Fora e Pocrane (Pinto et al. 2001, Noce et al. 2006, 2007). O milonito-gnaisse tonalítico dos arredores de Governador Valadares é candidato a pertencer à Suíte G1, embora apresente idade de ca. $560 \mathrm{Ma}$ (Silva et al. 2002, 2005). Também a esta suíte são relacionados corpos tonalíticos da região de Caratinga (Pinto et al. 2001), Manhuaçu (Noce et al. 2006) e Carangola (Novo et al. 2007). O grande corpo de orto-anfibolito (metagabro) de Santo Antônio do Grama tem idade-modelo Sm-Nd em torno de $890 \mathrm{Ma}$, sendo assim um candidato a resto ofiolítico neoproterozóico (Fischel et al. 1998). Os paragnaisses ricos em plagioclásio do Grupo Andrelândia forneceram idade-modelo Sm-Nd em torno de 1,3 Ga, sugestiva de mistura de fontes envolvendo sedimentos provenientes do arco magmático representado pela Suíte G1 (Fischel et al. 1998, Noce et al. 2006).

O estágio sin-colisional é caracterizado pela deformação e metamorfismo regionais, além de extensiva granitogênese do tipo $\mathrm{S}$, que ocorreram entre ca. 582 e 560 Ma (e.g., Nalini et al. 2000, PedrosaSoares \& Wiedemann-Leonardos 2000, Pedrosa-Soares et al. 2001, Campos et al. 2004, Silva et al. 2005). Neste estágio foram impressas as feições relacionadas ao dobramento e empurrões rumo a oeste, contra o Cráton do São Francisco, e também no sentido leste, contra o Cráton do Congo, além do metamorfismo relacionado às paragêneses minerais que materializam a foliação regional (Pedrosa-Soares et al. 2001, 2008, Alkmim et al. 2006, 2007, Vieira 2007). O metamorfismo regional mostra aumento de temperatura crescente desde a fácies xisto verde baixo, junto ao limite cratônico, à fácies anfibolito alto e granulito no núcleo do orógeno. Desta forma, em termos gerais, o metamorfismo no Orógeno Araçuaí cresce de oeste para leste e de norte para sul (Almeida et al. 1978, Pedrosa-Soares et al. 1984, 1992, 2001, Trompette 1994, Pedrosa-Soares \& Wiedemann-Leonardos 2000, Pinto et al. 2001). Dados geotermobarométricos quantitativos indicam condições de metamorfismo em torno de $530-600{ }^{\circ} \mathrm{C}$ a 5,5 kbar na Formação Ribeirão da Folha (PedrosaSoares 1995, Queiroga et al. 2006), $470-640{ }^{\circ} \mathrm{C} \mathrm{a} \mathrm{4,5-5}$ kbar no Grupo Rio Doce e $770-930{ }^{\circ} \mathrm{C}$ a $5-7$ kbar nos 
complexos Jequitinhonha e Nova Venécia (Munhá et al. 2005, Castañeda et al., em preparação), ao passo que na Formação Salinas ocorre uma zona de baixa pressão (3-4 kbar) com temperatura variável entre 450 e $650{ }^{\circ} \mathrm{C}$ (Costa 1989, Pedrosa-Soares et al. 1996; mas, localmente, o metamorfismo da Formação Salinas é de fácies xisto verde baixo, Lima et al. 2002).

A Suíte G2, que engloba a granitogênese tipo S do estágio sin-colisional, é constituída essencialmente de granito peraluminoso (com granada onipresente e cordierita e/ou sillimanita freqüentes), tendo granito a duas micas e granodiorito granatífero subordinados (Fig. 2, 4 e 5). Xenólitos e roof-pendants de rochas encaixantes são muito freqüentes. Os granitos G2 ocorrem em batólitos, corpos tabulares e stocks que registram a deformação regional marcada por foliação em estado sólido, muitas vezes milonítica e geralmente paralela à prévia orientação de fluxo ígneo (Nalini et al. 2000, Celino et al. 2000, Pedrosa-Soares \& Wiedemann- tardi- a pós-colisional do Orógeno Araçuaí (PedrosaSoares \& Wiedemann-Leonardos 2000, Pedrosa-Soares et al. 2001, 2006, Castañeda et al. 2006, Silva et al. 2007). As rochas típicas da Suíte G3 são leucogranitos com granada e/ou cordierita, pobres em micas e livres da foliação regional. Entretanto, variedades de granito micáceo, granatífero, com foliação incipiente, podem também pertencer a esta suíte. Idades U-Pb de leucogranitos G3 indicam cristalização magmática no intervalo 545-520 Ma (Whittington et al. 2001, Silva et al. 2005, 2007, Castañeda et al. 2006, Pedrosa-Soares et al.2006). Feições petrográficas e estruturais evidenciam que os cordierita-granada leucogranitos G3 são produtos autóctones e parautóctones da fusão parcial de granitos G2 deformados, em episódio pós-cinemático à foliação regional. Evidências disto são as relações de corte e superposição de G3 em G2 e as presenças, em G3, de restos não digeridos e traços de foliação (schlieren) de $\mathrm{G} 2$, e de granada (com inclusões de fibrolita

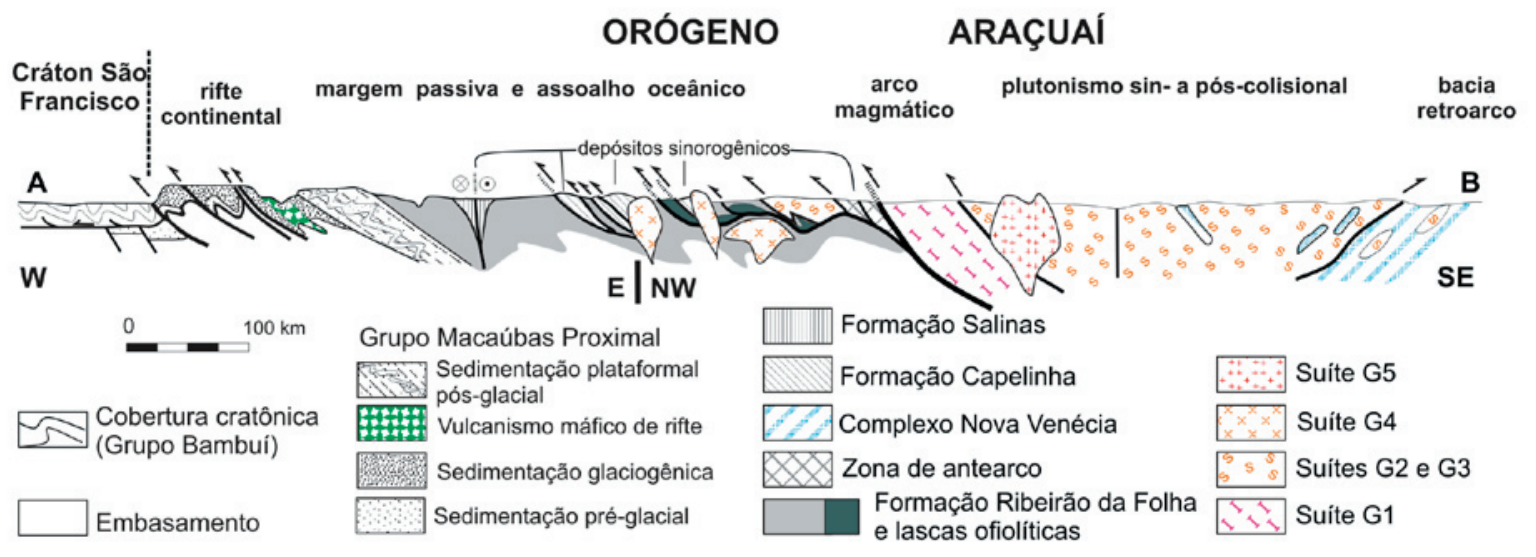

Figura 5. Componentes geotectônicos do Orógeno Araçuaí representados em perfil (modificado de PedrosaSoares et al. 2008). AB está localizado na Figura 2.

Leonardos 2000, Pedrosa-Soares et al. 2001, 2006, Pinto et al. 2001, Campos et al. 2004, Castañeda et al. 2006). Entretanto, batólitos G2 podem mostrar feições ígneas bem preservadas, particularmente em suas porções interiores, que têm a mesma idade de cristalização magmática dos termos milonitizados (Pedrosa-Soares et al. 2006, Roncato et al. 2007, Vauchez et al. 2007). Dados geotermobarométricos sugerem que os granadabiotita granitos da Suíte G2 se cristalizaram e ganharam a foliação dúctil regional em temperaturas entre $640 \mathrm{e}$ $680{ }^{\circ} \mathrm{C}$ (Castañeda et al., em preparação). Idades U-Pb indicam que a época de maior formação dos granitos G2 ocorreu em torno de $575 \mathrm{Ma}$ (Silva et al., 2002, 2005, Pedrosa-Soares et al. 2006, Roncato et al. 2007, Vauchez et al. 2007), mas alguns corpos G2 são mais antigos (ca. $582 \mathrm{Ma}$; Nalini et al. 2000) e outros mais jovens (ca. 560 Ma; Söllner et al. 1991, Campos et al. 2004, Silva et al. 2005). O grande distrito pegmatíticogemológico de Conselheiro Pena-Galiléia pertence à Suíte G2 (Pedrosa-Soares et al. 2001).

Os produtos da granitogênese G3, do tipo S, estão representados pela Suíte G3 que teve origem no período dobrada) herdada de G2 (ver fotos em Castañeda et al. 2006 e Pedrosa-Soares et al. 2006). Aglomerados compostos quase exclusivamente por cordierita, granada, sillimanita, monazita e apatita representam resíduos granulíticos associados a leucogranitos G3. Dados geotermobarométricos indicam que os leucogranitos G3 se cristalizaram a temperatura bem mais alta que a Suíte $\mathrm{G} 2$, em torno de $815^{\circ} \mathrm{C}$ a $5 \mathrm{kbar}$ (Castañeda et al., em preparação). Veios graníticos e pegmatitos, livres da foliação regional, encaixados no Complexo Nova Venécia, podem ser correlatos da Suíte G3, e representariam produtos da fusão parcial deste complexo (Pedrosa-Soares et al. 2006). A Suíte G3 registra herança de fontes paragnáissicas envolvidas em processos de fusão parcial, evidenciada por cristais de zircão com núcleos herdados de idades entre $630 \mathrm{Ma}$ e $850 \mathrm{Ma}$, além de componentes paleoproterozóicos e arqueanos (Silva et al. 2007).

No estágio pós-colisional ocorreram processos deformacionais (Marshak et al. 2006, Alkmim et al. 2007) e plutonismo relacionados ao colapso gravitacional (extensional) do Orógeno Araçuaí 
(Pedrosa-Soares \& Wiedemann-Leonardos 2000, Pedrosa-Soares et al. 2001, Campos et al. 2004). Neste estágio formaram-se as suítes G4 e G5 que são constituídas por plútons intrusivos, livres da foliação regional (embora a foliação de borda e/ou fluxo ígneo possam, localmente, ser concordantes com a foliação regional). Muitas destas intrusões são circunscritas pela foliação regional, a qual conformam em torno de seus contatos. Grandes distritos pegmatíticos produtores de gemas e minerais industriais estão relacionados às suítes G4 e G5 (Pedrosa-Soares et al. 2001).

A Suíte G4, do tipo S, é composta essencialmente por granitos a duas micas que, localmente, preservam cúpulas de granito pegmatóide ou raízes de biotita granito, os quais compõem intrusões hospedadas, principalmente, pelas formações Ribeirão da Folha e Salinas (Fig. 2, 4 e 5). As idades disponíveis indicam o intervalo de 535-500 Ma para a granitogênese G4 (Pedrosa-Soares et al. 1987, 2001, Grossi-Sad et al. 1997, Pedrosa-Soares 1997, Pedrosa-Soares \& Oliveira 1997, Basílio et al. 2000, Pedrosa-Soares \& WiedemannLeonardos 2000, Pinto et al. 2001, Whittington et al. 2001, Campos et al. 2004, Silva et al. 2005). As intrusões G4 são em parte contemporâneas da Suíte G3 e podem ser consideradas como correspondentes alóctones, cristalizados em níveis crustais superiores, em relação aos corpos autóctones a parautóctones da Suíte G3. Neste sentido, destaca-se a composição mais hidratada do magma G4 (granito a duas micas; PedrosaSoares et al. 1987) em relação ao G3 (granada-cordierita leucogranito livre de micas primárias; Castañeda et al. 2006, Pedrosa-Soares et al. 2006), bem como a consangüinidade dos granitos G4 com pegmatitos litiníferos que são característicos de profundidades inferiores a $12 \mathrm{~km}$ (Correia-Neves et al. 1986).

A Suíte G5 representa o plutonismo tipo I e A2, cálcio-alcalino rico em potássio e ferro, do estágio pós-colisional do Orógeno Araçuaí (Fig. 2, 4 e 5). As intrusões G5 têm composição predominantemente granítica ou charnockítica, com termos enderbíticos e noríticos subordinados, que apresentam diversas evidências de misturas (mingling e mixing) de magmas e fluxo ígneo geralmente bem marcado. Intrusões zonadas que expõem raízes máficas, assim como corpos exclusivamente noríticos, são freqüentes na região sudeste do orógeno. A norte do paralelo $19^{\circ} \mathrm{S}$ predominam grandes batólitos dominados por biotita granito ou charnockito de granulação grossa. A Suíte G5 originou-se no intervalo 520-490 Ma, relacionado ao colapso gravitacional do Orógeno Araçuaí, e apresenta atributos isotópicos $\mathrm{Sm}-\mathrm{Nd}$ e $\mathrm{Rb}-\mathrm{Sr}$ que evidenciam origem híbrida resultante da mistura de magmas mantélicos e crustais (Wiedemann 1993, Pinto et al. 1997, 2001, Pedrosa-Soares \& Wiedemann-Leonardos 2000, Wiedemann-Leonardos et al. 2000, Noce et al. 2000, Medeiros et al. 2001, Pedrosa-Soares et al. 2001, 2006, Wiedemann et al. 2002, Campos et al. 2004, Martins et al. 2004, Mendes et al. 2005, Silva et al. 2005, 2007).
A enorme quantidade e variedade de rochas graníticas do Orógeno Araçuaí fez dele palco da maior produção de rochas ornamentais do Brasil, com destaque para as regiões norte do Espírito Santo e nordeste de Minas Gerais, e para as suítes G2 (especialmente, os materiais amarelos do batólito Carlos Chagas), G3 (materiais brancos), G4 (granito pegmatóide e grandes pegmatitos) e G5 (materiais verdes e amarelas), (e.g., Costa \& Pedrosa-Soares 2006).

\section{CONCLUSÃO}

O Orógeno Araçuaí revela-se como uma das regiões orogênicas mais bem conhecidas do Brasil, após três décadas de mapeamento geológico e estudos científicos. A estratigrafia regional (Fig. 2, 3 e 4) e os componentes geotectônicos já caracterizados (Fig. 5 e 6) demonstram o quão completo é o registro litológico do Orógeno Araçuaí. Por sua vez, a Faixa Congo Ocidental é desprovida de muitos componentes geotectônicos que ocorrem apenas no território brasileiro e, por isto, caracteriza-se como uma faixa de dobramentos e empurrões complementar ao Orógeno Araçuaí (Fig. 6).

Entretanto, a grande quantidade de rochas magmáticas anorogênicas que se encontra na Faixa Congo Ocidental indica que o rifte continental precursor foi assimétrico e que seu eixo térmico situou-se na África (i.e., o lado africano comportou-se como upper plate; Pedrosa-Soares et al. 2008). A diferença de idade (ca. $30 \mathrm{Ma}$ ) entre os granitos tipo A de Salto da Divisa (ca. $875 \pm 9 \mathrm{Ma}$; Silva et al. 2007) e as rochas vulcânicas félsicas anorogênicas mais jovens da Faixa Congo Ocidental (912 \pm 7 Ma; Tack et al. 2001) sugere que o eixo térmico do rifte migrou rumo à contraparte Araçuaí. Uma conseqüência desta migração seria o vulcanismo básico transicional do Membro Rio Preto, que ocorreu no estágio rifte tardio, sucedido pela oceanização do setor meridional da bacia Macaúbas.

O arco magmático e os restos ofiolíticos do Orógeno Araçuaí têm terminação setentrional em torno do paralelo $17^{\circ} 30^{\prime} \mathrm{S}$ e sua posição relativa indica subducção da litosfera oceânica para leste, sendo a zona de sutura balizada pelo meridiano $42^{\circ} \mathrm{W}$ (na orientação geográfica atual). A terminação setentrional destes componentes geotectônicos sugere que o setor norte da bacia precursora permaneceu ensiálico, a exemplo de golfos atuais apenas parcialmente oceanizados. Além disso, a geoquímica isotópica do $\mathrm{Nd}$ indica pouca influência de material juvenil na constituição do arco magmático do Orógeno Araçuaí (e.g., Cordani et al. 2000, Nalini et al. 2000, Campos et al. 2004, Martins et al. 2004), sugerindo também que o espalhamento oceânico na bacia precursora foi restrito. Com efeito, todas as reconstruções paleogeográficas disponíveis na literatura mostram os crátons São Francisco e Congo interligados na altura de Bahia e Gabão, de tal modo que o Paleocontinente São Francisco-Congo atuou como peça única na trama paleocontinental do 


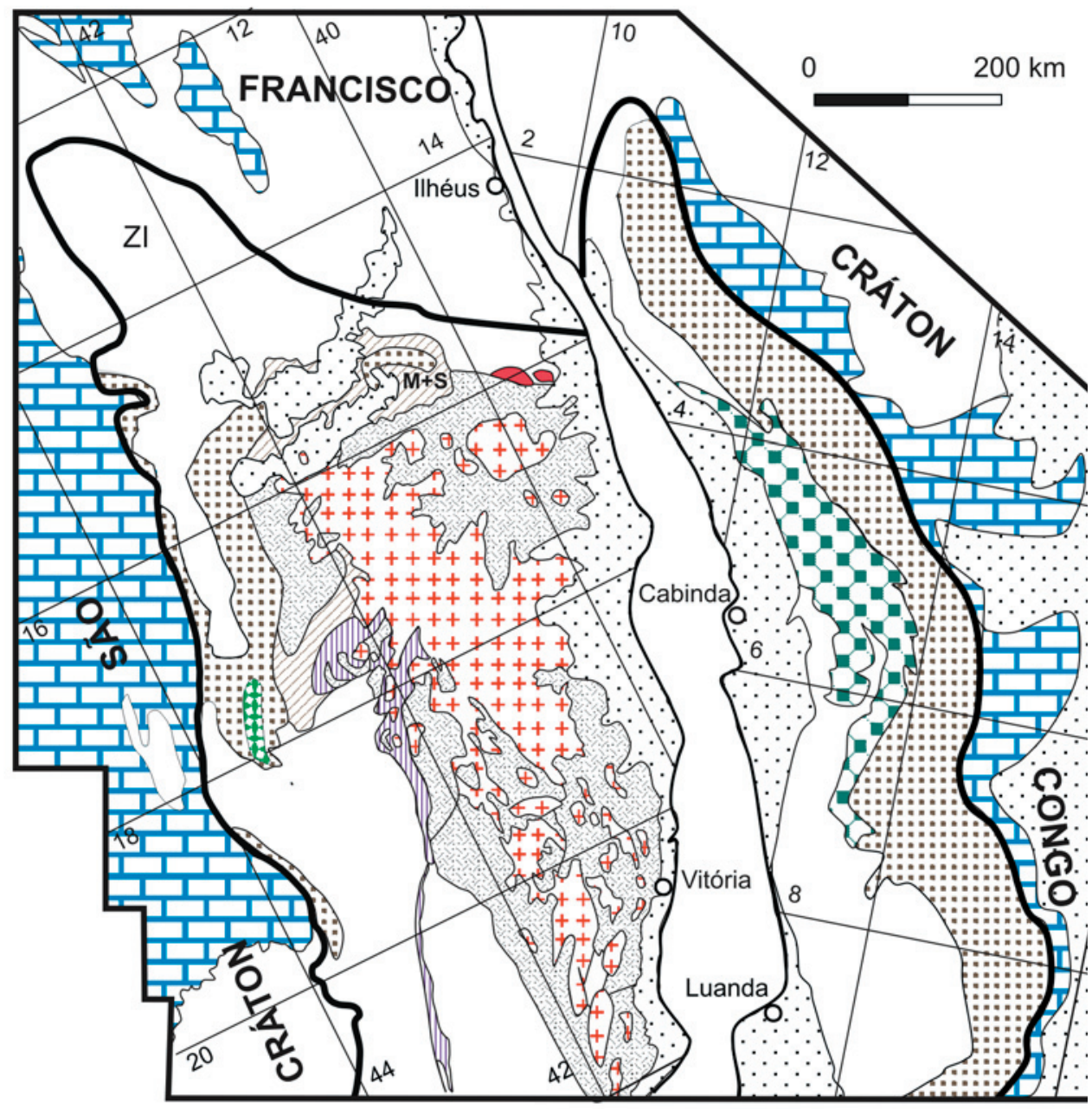

\section{ARAÇUAÍ OROGEN}

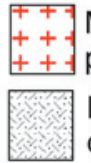

Magmatismo orogênico

pré- a pós-colisional

Bacias sin-orogênicas e remanescentes

de margem passiva

Margem passiva distal e assoalho oceânico

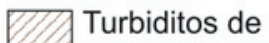

mar profundo

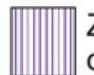

Zona com lascas ofiolíticas

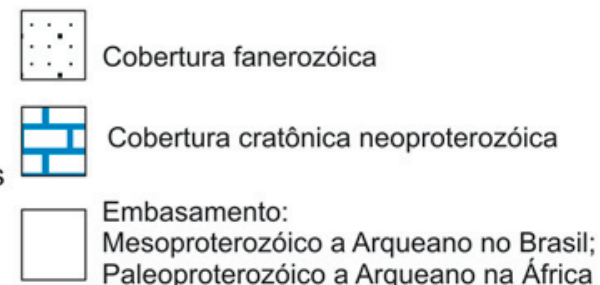

FAIXA CONGO OCIDENTAL

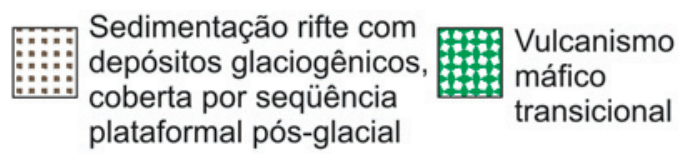

Plutonismo de rifte continental

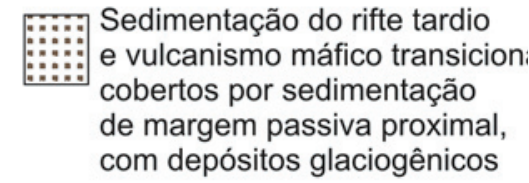

Vulcanismo e plutonismo
de rifte continental

Figura 6. Principais componentes geotectônicos do Orógeno Araçuai e sua correlação com a Faixa Congo Ocidental (modificado de Pedrosa-Soares et al., 2008).

Neoproterozóico (e.g., D’Agrella-Filho et al. 1990, 2004, Dalziel 1997, Cordani et al. 2003, Meert \& Torsvik 2003, Pisarevsky et al. 2003). Neste cenário, a bacia precursora do Orógeno Araçuaí era um golfo parcialmente oceanizado (uma inland-sea basin). $\mathrm{O}$ orógeno que sucedeu a esta bacia se caracteriza, então, como um tipo especial de edifício colisional: o orógeno confinado (Pedrosa-Soares et al. 2001, 2003, Rogers \& Santosh 2004).

A peculiar situação geotectônica do orógeno 
confinado Araçuaí-Congo Ocidental, bem como o pequeno tamanho de sua litosfera oceânica (que por si só seria incapaz de promover subducção), aliados ao significativo acervo de dados tectônicos, inspiraram Alkmim et al. $(2003,2006)$ a elaborar um novo mecanismo para a edificação do Orógeno Araçuaí: a Tectônica Quebra-Nozes (ver também Alkmim et al. 2007, neste volume).

\section{AGRADECIMENTOS}

Os autores agradecem ao CNPq, CT-Infra, FINEP, FAPEMIG, FAPESP, CAPES, CODEMIG, MMECPRM-Programa Geologia do Brasil e PrPq-UFMG pelos recursos financeiros à pesquisa científica, bolsas e projetos de mapeamento geológico.

\section{REFERÊNCIAS BIBLIOGRÁFICAS}

Alkmim, F.F., Brito-Neves, B.B. \& Alves, J.A.C. 1993. Arcabouço Tectônico do Cráton do São Francisco: uma revisão. In: J.M.L. Dominguez \& A. Misi. (org.), O Cráton do São Francisco. Salvador, SBG-BA, p. 45-62.

Alkmim, F.F., Marshak, S., Pedrosa-Soares, A.C., Cruz, S.C.P.; Peres, G.G. \& Whittington, A.G. 2003. Tectônica Quebra-Nozes e a Gênese do Orógeno Araçuaí-Congo Ocidental. In: Simpósio Nacional de Estudos Tectônicos, 9 , Búzios. SBG-RJ, Boletim de Resumos, p. 40-43.

Alkmim, F.F., Marshak, S., Pedrosa-Soares, A.C., Peres, G.G., Cruz, S.C.P. \& Whittington, A. 2006. Kinematic evolution of the Araçuaí-West Congo orogen in Brazil and Africa: Nutcracker tectonics during the Neoproterozoic assembly of Gondwana. Precambrian Research, 149: 43-63.

Alkmim, F.F., Pedrosa-Soares, A.C., Noce, C.M. \& Cruz, S.C.P. 2007. Sobre a Evolução Tectônica do Orógeno Araçuaí-Congo Ocidental. Geonomos, 15: neste número.

Almeida, F.F.M. 1977. O Cráton do São Francisco. Revista Brasileira de Geociências, 7: 349-364.

Almeida, F.F.M., Hasui, Y., Rodrigues, E.P. \& Yamamoto, J. 1978 A Faixa de Dobramentos Araçuaí na região do Rio Pardo. In: Congresso Brasileiro de Geologia, 30, Recife. SBG, Anais, v. 1, p. $270-283$.

Almeida, F.F.M. \& Hasui, Y. 1984, O Pré-Cambriano do Brasil. São Paulo, Edgard Blücher, 378 p.

Angeli, N., Teixeira, W., Heaman, L., Fleet, M.E., Moore, M. \& Sato, K. 2004. Geochronology of the Ipanema Layered Mafic-Ultramafic Complex, Minas Gerais, Brazil: Evidence of extension at the Meso-Neoproterozoic time boundary. International Geology Review, 46: 730-744.

Aracema, L.W., Neves, A.C., Ferreira, J.C., Pedrosa-Soares, A.C., Lobato, L.M. \& Noce, C.M. 2000. Novas evidências de remanescentes oceânicos na Faixa Araçuaí: As rochas metaultramáficas de São José da Safira. Geonomos, 8 (1): 55-61.

Babinski, M., Gradim, R.J., Pedrosa-Soares, A.C., Alkmim, F.F., Noce, C.M. \& Liu, D. 2005. Geocronologia U-Pb (SHRIMP) e Sm-Nd de xistos verdes basálticos do Orógeno Araçuaí: Implicações para a idade do Grupo Macaúbas. Revista Brasileira de Geociências, 35 (4-suplemento): 77-81.

Babinski, M., Pedrosa-Soares, A.C., Martins, M., Liu, D., Noce, C.M. \& Karfunkel. J. 2007. U-Pb SHRIMP dating of detrital zircons from the Macaúbas Group, southeast Brazil: implications on the depositional age and provenance of pre-glacial and glaciogenic sediments. In: Symposium on Neoproterozoic-Early Palaeozoic Events in SW Gondwana, 3, IGCP-478, Stellenbosch, South Africa.

Barbosa, A.L.M., Grossi-Sad, J.H. \& Torres, N. 1964. Geologia das quadrículas de Barra do Cuieté e Conselheiro Pena, Minas Gerais. Belo Horizonte, DNPM-GEOSOL, 285 p.
Barbosa, J.S.F. \& Dominguez, J.M.L. 1996. Texto Explicativo do Mapa Geológico da Bahia escala 1:1.000.000. Salvador, Companhia Bahiana de Pesquisa Mineral, 382 p.

Basílio, M.S., Pedrosa-Soares, A.C. \& Evangelista, H.J. 2000. Depósitos de alexandrita de Malacacheta, Minas Gerais. Geonomos, 8 (1): 47-54.

Brito Neves, B.B. \& Cordani, U.G. 1991. Tectonic evolution of South America during the Late Proterozoic. Precambrian Research, 53: 23-40.

Brito-Neves, B.B., Campos-Neto, M.C. \& Fuck, R.A. 1999. From Rodinia to Western Gondwana: An approach to the BrasilianoPan African cycle and orogenic collage. Episodes, 22: 155199.

Campos, C.M., Mendes, J.C., Ludka, I.P., Medeiros, S.R., Moura, J.C. \& Wallfass, C. 2004. A review of the Brasiliano magmatism in southern Espírito Santo, Brazil, with emphasis on postcollisional magmatism. Journal of the Virtual Explorer, 17: 1-35.

Campos-Neto, M.C. \& Figueiredo M.C.H. 1995. The Rio Doce orogeny, southeastern Brazil, Journal South American Earth Science, 8: 143-162.

Castañeda, C., Pedrosa-Soares, A.C., Belém, J., Vieira, V.S., Queiroga, G. (em preparação). Geothermobarometry of metapelites and granites from the Araçuaí Orogen: implications for PTT paths in a confined orogen.

Castañeda, C., Pedrosa-Soares, A.C., Belém, J., Gradim, D., Dias, P.H.A., Medeiros, S.R., Oliveira, L. 2006. Geologia da Folha Ecoporanga 1:100.000. Rio de Janeiro, CPRM-Serviço Geológico do Brasil, UFMG-Programa Geologia do Brasil.

Celino, J.J., Botelho, N. F. \& Pimentel, M. M. 2000. Genesis of Neoproterozoic Granitoid Magmatism in the Eastern Araçuaí Fold Belt, Eastern Brazil: Field, Geochemical and Sr-Nd Isotopic Evidence. Revista Brasileira de Geociencias, 30: 135-139.

Cordani, U., Sato, K., Teixeira, W., Tassinari, C.C.G. \& Basei, M.A.S. 2000. Crustal evolution of the South American Platform. In: U. Cordani, E. Milani, A. Thomaz-Filho \& D. A. Campos (eds), Tectonic Evolution of South America. São Paulo, Sociedade Brasileira de Geologia, p. 19-40.

Cordani, U.G., Brito-Neves, B.B., D’Agrella, M.S. \& Trindade, R.I.F. 2003. Tearing-up Rodinia: the Neoproterozoic paleogeography of South American cratonic fragments. Terra Nova, 15: 343-349.

Correia-Neves, J.M., Pedrosa-Soares, A.C. \& Marciano, V.R. 1986. A Província Pegmatitica Oriental do Brasil à luz dos conhecimentos atuais. Revista Brasileira de Geociencias, 16 (1): 106-118.

Costa, A.G. 1989. Evolução petrológica para uma sequência de rochas metamórficas regionais do tipo baixa pressão, Itinga, NE-MG. Revista Brasileira de Geociências, 19: 440-448.

Costa, A.G. \& Pedrosa-Soares, A.C. 2006. Catálogo de Rochas Ornamentais da Região de Barra do São Francisco-EcoporangaNova Venécia, norte do Espírito Santo. Rio de Janeiro, CPRMServiço Geológico do Brasil, UFMG-Programa Geologia do Brasil.

CPRM-CODEMIG 2003. Mapa Geológico de Minas Gerais, escala 1:1.000.000. Belo Horizonte, Companhia de Desenvolvimento Econômico de Minas Gerais, CD-ROM.

Cunningham, D., Alkmim, F. F. \& Marshak, S. 1998. A structural transect across the coastal mobile belt in the Brazilian Highlands (latitude $20^{\circ} \mathrm{S}$ ): The roots of a Precambrian transpressional orogen. Precambrian Research, 92: 251-275.

D’Agrella-Filho, M.S., Pacca, I.G., Renne, P.R., Onstott, T.C. \& Teixeira, W., 1990. Paleomagnetism of middle Proterozoic (1.01$1.08 \mathrm{Ga}$ ) mafic dykes in southeastern Bahia state, Sao Francisco craton, Brazil. Earth Planet. Sci. Letters 101: 332-348.

D’Agrella Filho, M.S., Pacca, I.G., Trindade, R.I.F., Teixeira, W., Raposo, M.I.B. \& Onstott, T.C. 2004. Paleomagnetism and ${ }^{40} \mathrm{Ar}^{39} \mathrm{Ar}$ ages of mafic dykes from Salvador (Brazil): new constraints on the São Francisco craton APW path between 1080 and 1010 Ma. Precambrian Research, 132: 55-77.

Daconti, B.C. 2004. Contexto geológico, controle e correlação regional das mineralizações de grafita da região de Almenara, Província Grafitica do Nordeste de Minas Gerais. Belo Horizonte, IGC-UFMG, Dissertação de Mestrado.

Dalziel, I.W.D. 1997, Neoproterozoic-Paleozoic geography and tectonics: Review, hypothesis, environmental speculation: Geological Society America Bulletin, 109: 16-42. 
Faria, L.F. 1997. Controle e tipologia de mineralizações de grafita flake do nordeste de Minas Gerais e sul da Bahia: uma abordagem regional. Belo Horizonte, IGC-UFMG, Dissertação de Mestrado.

Fischel, D.P., Pimentel, M.M., Fuck, R.A., Costa, A.G. \& Rosière, C.A. 1998. Geology and Sm-Nd isotopic data for the Mantiqueira and Juiz de Fora Complexes (Ribeira Belt) in the Abre CampoManhuaçu region, Minas Gerais, Brazil. In: International Conference on Basement Tectonics, 14, Ouro Preto. UFOP, Extended Abstracts, p. 21-23.

Gradim, R.J., Alkmim, F.F., Pedrosa-Soares, A.C., Babinski, M. \& Noce, C.M. 2005. Xistos Verdes do Alto Araçuaí, Minas Gerais: Vulcanismo Básico do Rifte Neoproterozóico Macaúbas. Revista Brasileira de Geociências, 35 (4-suplemento): 59-69.

Grossi-Sad, J.H., Lobato, L.M., Pedrosa-Soares, A.C. \& Soares-Filho, B.S. 1997 (eds). Projeto Espinhaço em CD-ROM. CODEMIG, Belo Horizonte, 2693 p. e 23 mapas.

Hasui, Y., Carneiro, C.D.R. \& Coimbra, A.M. 1975. The Ribeira Fold Belt. Revista Brasileira de Geociências, 5: 257-266.

Heilbron, M.L., Pedrosa-Soares, A.C., Campos Neto, M.C., Silva, L.C., Trouw, R. \& Janasi, V.A. 2004. Província Mantiqueira. In: V.M. Mantesso-Neto, A. Bartorelli, C.D.R. Carneiro \& BritoNeves, B.B. (orgs.). Geologia do Continente Sul-Americano. São Paulo, Editora Beca, p. 203-234.

Horn, A.H. 2006. Geologia da Folha Espera Feliz 1:100.000. Rio de Janeiro, CPRM-Serviço Geológico do Brasil, UFMG-Programa Geologia do Brasil.

Inda, H.A.V. \& Barbosa, J. 1978. Mapa Geológico do Estado da Bahia, Texto Explicativo. Salvador, Secretaria de Minas e Energia, Coordenação da Produção Mineral, 122 p.

Karfunkel, J., Pedrosa-Soares, A.C. \& Dossin, I.A. 1985. O Grupo Macaúbas em Minas Gerais: revisão dos conhecimentos. Boletim do Núcleo Minas Gerais-Sociedade Brasileira de Geologia, 5: 45-59.

Karfunkel, J. \& Hoppe, A. 1988. Late Precambrian glaciation in central-eastern Brazil: Synthesis and model. Palaeogeography Palaeoclimatology Palaeoecology, 65: 1-21.

Ledru, P.J., Johan, V., Milési, J.P. \& Teguy, M. 1994. Markers of the last stage of the Paleoproterozoic collision: Evidence for a 2 Ga continent involving circum-South Atlantic provinces. Precambrian Research, 69: 169-191.

Lima, S.A.A., Martins-Neto, M.A., Pedrosa-Soares, A.C., Cordani, U.G. \& Nutman A. 2002. A Formação Salinas na área-tipo, NE de Minas Gerais: Uma proposta de revisão da estratigrafia da Faixa Araçuaí com base em evidências sedimentares, metamórficas e idades U-Pb SHRIMP. Revista Brasileira de Geociências, 32: 491-500.

Machado, N., Schrank, A., Abreu, F.R., Knauer, L.G. \& AlmeidaAbreu, P.A. 1989. Resultados preliminares da geocronologia U$\mathrm{Pb}$ na Serra do Espinhaço Meridional. Boletim do Núcleo Minas Gerais-Sociedade Brasileira de Geologia, 10: 171-174.

Marshak, S., Alkmim, F.F., Whittington, A. \& Pedrosa-Soares, A.C. 2006. Extensional collapse in the Neoproterozoic Araçuaí orogen, eastern Brazil: A setting for reactivation of asymmetric crenulation cleavage. Journal Structural Geology, 28: 129147.

Martins, M.S. 2006. Geologia dos diamantes e carbonados aluvionares da bacia do Rio Macaúbas, MG. Belo Horizonte, IGC-UFMG, Tese de Doutorado.

Martins, V.T.S., Teixeira, W., Noce, C.M. \& Pedrosa-Soares, A.C. 2004. Sr and Nd characteristics of Brasiliano-Pan African granitoid plutons of the Araçuaí orogen, southeastern Brazil: Tectonic implications. Gondwana Research, 7: 75-89.

Martins-Neto, M.A., Pedrosa-Soares, A.C. \& Lima, S.A.A. 2001. Tectono-sedimentary evolution of sedimentary basins from Late Paleoproterozoic to Late Neoproterozoic in the São Francisco craton and Araçuaí fold belt, eastern Brazil. Sedimentary Geology, 141/142: 343-370.

Martins-Neto, M.A. \& Hercos, C.M. 2002. Sedimentation and tectonic setting of Early Neoproterozoic glacial deposits in southeastern Brazil. International Association of Sedimentologists, Special Publication, 33: 383-403.

Meert, J.G. \& Torsvik, T.H. 2003. The making and unmaking of a supercontinent: Rodinia revisited. Tectonophysics, 375:
261-288.

Medeiros, S.R., Wiedemann, C. \& Vriend, S. 2001. Evidence of mingling between contrasting magmas in a deep plutonic environment: the example of Várzea Alegre, in the Pan-Africa/ Brasiliano Mobile Belt in Brazil. Anais Academia Brasileira Ciências, 73: 99-119.

Mendes, J.C., Medeiros, S.R. \& McReath, I. 2005. Cambro-Ordovician Magmatism in SE Brazil: U-Pb and Rb-Sr Ages, Combined with $\mathrm{Sr}$ and $\mathrm{Nd}$ isotopic data of charnockitic rocks from Várzea Alegre Complex. Gondwana Research, 8: 337-349.

Mourão, M.A.A. \& Pedrosa-Soares, A. C. 1992. Evidências de sedimentação turbidítica no Grupo Macaúbas, Faixa Araçuaí. Revista Escola de Minas de Ouro Preto, 45: 94-96.

Munhá, J.M.U, Cordani, U.G., Tassinari, C.C.G \& Palácios, T. 2005. Petrologia e termocronologia de gnaisses migmatíticos da Faixa de Dobramentos Araçuaí (Espírito Santo, Brasil). Revista Brasileira de Geociências, 35: 123-134.

Nalini, H.A. 1997. Caractérisation des suites magmatiques néoprotérozoïques de la région de Conselheiro Pena et Galiléia (Minas Gerais, Brésil) : étude géochimique et structurale des suites Galiléia et Urucum et leur relation avec les pegmatites à éléments rares associées. École des Mines de Saint-Étienne et École des Mines de Paris, Thèse.

Nalini, H.A., Bilal, E., Paquette, J.L., Pin, C. \& Machado, R. 2000 Geochronologie $\mathrm{U}-\mathrm{Pb}$ et géochimie isotopique $\mathrm{Sr}-\mathrm{Nd}$ des granitoides neoproterozoiques des suites Galileia et Urucum, vallée du Rio Doce, Sud-Est du Brésil. Compte Rendu Academie Science Paris, 331: 459-466.

Nalini, H. A., Bilal, E. \& Correia-Neves, J.M. 2000. Syncollisional peraluminous magmatism in the Rio Doce region: mineralogy, geochemistry and isotopic data of the Urucum suite (eastern Minas Gerais State, Brazil). Revista Brasileira de Geociencias, 30: $120-125$

Nalini, H.A., Machado, R.M. \& Bilal, E. 2005. Geoquímica e petrogênese da Suíte Galiléia: exemplo de magmatismo tipo-I, metaluminoso, pré-colisional, neoproterozóico, da região do Médio Vale do Rio Doce. Revista Brasileira de Geociências, 35 (4-suplemento), 23-34.

Noce, C.M., Pedrosa-Soares, A.C., Grossi-Sad, J.H., Baars, F.J., Guimarães, M.V., Mourão, M.A.A., Oliveira, M.J.R. \& Roque, N.C. 1997. Nova Subdivisão Estratigráfica Regional do Grupo Macaúbas na Faixa Araçuaí: O Registro de uma Bacia Neoproterozóica. Boletim do Núcleo Minas Gerais-Sociedade Brasileira de Geologia, 14: 29-31.

Noce, C.M., Macambira, M.B. \& Pedrosa-Soares, A.C. 2000. Chronology of Neoproterozoic-Cambrian granitic magmatism in the Araçuaí Belt, Eastern Brazil, based on single zircon evaporation dating. Revista Brasileira de Geociências, 30 : 25-29.

Noce, C.M, Pedrosa-Soares, A.C., Piuzana, D., Armstrong, R., Laux, J.H. Campos, C.M. \& Medeiros, S.R. 2004. Ages of sedimentation of the kinzigitic complex and of a late orogenic thermal episode in the Araçuaí orogen, northern Espírito Santo State, Brazil: Zircon and monazite U-Pb SHRIMP and ID-TIMS data. Revista Brasileira de Geociencias, 349: 587-592.

Noce, C.M., Costa, A.G., Piuzana, D., Vieira, V.S. \& Carvalho, C. 2006. Geologia da Folha Manhuaçu 1:100.000. Rio de Janeiro, CPRM-Serviço Geológico do Brasil, UFMG-Programa Geologia do Brasil.

Noce, C.M., Pedrosa-Soares, A.C., Silva, L.C., Armstrong, R. \& Piuzana, D. 2007. Evolution of polyciclic basement complexes in the Araçuaí orogen, based on U-Pb SHRIMP data: Implications for Brazil-Africa links in Paleoproterozoic time. Precambrian Research (no prelo, doi:10.1016/j.precamres.2007.06.001).

Noce, C.M., Pedrosa-Soares, A.C., Silva, L.C. \& Alkmim, F.F. 2007. O Embasamento Arqueano e Paleoproterozóico do Orógeno Araçuaí. Geonomos, 15 (este número).

Novo, T.A., Roncato, J., Bhering, A.P., Carvalho, C.M., Cordeiro, E.Z., Carneiro, G.A., Pereira, M.A.S., Coelho, V.P., PedrosaSoares, A.C. \& Noce, C.M. 2007. Rochas charno-enderbíticas da região de Carangola: Implicações para a conexão AraçuaíRibeira. In: Simpósio de Geologia do Sudeste, 10, Diamantina. SBG-MG, Resumos.

Paixão, M.M. \& Perrella, P. 2004. Mapeamento geológico da área do 
contato entre o Maciço Granítico Salto da Divisa e o Complexo Jequitinhonha, Nordeste de Minas Gerais. Belo Horizonte, IGCUFMG, Trabalho de Graduação.

Pedrosa-Soares, A.C., Leonardos, O. H. \& Correia-Neves, J.M. 1984. Aspectos metamórficos de sequências supracrustais da Faixa Araçuaí em Minas Gerais. In: Congresso Brasileiro de Geologia, 33, Rio de Janeiro. SBG, Anais, v. 7, p. 3056-3068.

Pedrosa-Soares, A.C., Monteiro, R., Correia-Neves, J.M., Leonardos, O.H. \& Fuzikawa, K. 1987. Metasomatic evolution of granites, northeast Minas Gerais, Brazil. Revista Brasileira de Geociências, 17: 512-518.

Pedrosa-Soares, A. C., Monteiro, R.L.B.P., Noce, C. M., Freitas-Silva, F.H., Oliveira, M.J.R. \& Schettino, A. 1990. Caracterização de uma seqüência vulcano-sedimentar distal na Faixa Araçuaí, MG: bacia oceânica restrita? In: Congresso Brasileiro de Geologia, 36, Natal. SBG, Boletim de Resumos, p. 308.

Pedrosa-Soares, A. C., Noce, C. M., Vidal, P., Monteiro, R. \& Leonardos, O. H. 1992. Toward a new tectonic model for the Late Proterzoic Araçuaí (SE Brazil) - West Congolian (SW Africa) Belt. Journal of South American Earth Sciences, 6: 33-47.

Pedrosa-Soares, A.C. 1995. Potencial aurifero do Vale do Araçuai, Minas Gerais: história da exploração, geologia e controle tectono-metamórfico. Brasília, IG-UnB, Tese de Doutorado.

Pedrosa-Soares, A.C., Leonardos, O.H., Ferreira, J.C. \& Reis, L.B. 1996. Duplo regime metamórfico na Faixa Araçuaí: Uma reinterpretação à luz de novos dados. In: Congresso Brasileiro de Geologia, 39, Salvador. SBG, Anais, v. 6, p. 5-8.

Pedrosa-Soares, A.C. 1997. Geologia da Folha Araçuaí. In: J.H. Grossi-Sad, L.M. Lobato, A.C. Pedrosa-Soares \& B.S. SoaresFilho (eds), Projeto Espinhaço em CD-ROM. Belo Horizonte, CODEMIG, p. 715-852.

Pedrosa-Soares, A.C. 1997. Geologia da Folha Jenipapo. In: J.H Grossi-Sad, L.M. Lobato, A.C. Pedrosa-Soares \& B.S. SoaresFilho (eds), Projeto Espinhaço em CD-ROM. Belo Horizonte, CODEMIG, p. 1053-1198.

Pedrosa-Soares, A.C. \& Grossi-Sad, J.H. 1997. Geologia da Folha Minas Novas. In: J.H. Grossi-Sad, L.M. Lobato, A.C. PedrosaSoares \& B.S. Soares-Filho (eds), Projeto Espinhaço em CD ROM. Belo Horizonte, CODEMIG, p. 952-1052.

Pedrosa-Soares, A.C. \& Oliveira, M.J.R. 1997. Geologia da Folha Salinas. In: J.H. Grossi-Sad, L.M. Lobato, A.C. Pedrosa-Soares \& B.S. Soares-Filho (eds), Projeto Espinhaço em CD-ROM. Belo Horizonte, CODEMIG, p. 419-542.

Pedrosa-Soares, A.C. \& Noce, C.M. 1998. Where is the suture zone of the Neoproterozoic Araçuaí-West-Congo orogen? In: Conference on Basement Tectonics, 14, Ouro Preto. UFOP, Extended Abstracts, p. 35-37.

Pedrosa-Soares, A.C., Vidal, P., Leonardos, O.H. \& Brito-Neves, B.B 1998. Neoproterozoic oceanic remnants in eastern Brazil: Further evidence and refutation of an exclusively ensialic evolution for the Araçuaí-West Congo orogen. Geology, 26: 519-522.

Pedrosa-Soares, A.C. \& Wiedemann-Leonardos, C.M. 2000 Evolution of the Araçuaí Belt and its connection to the Ribeira Belt, Eastern Brazil. In: U. Cordani, E. Milani, A. Thomaz-Filho \& D. A. Campos (eds), Tectonic Evolution of South America. São Paulo, Sociedade Brasileira de Geologia, p. 265-285.

Pedrosa-Soares, A.C., Cordani, U. \& Nutman, A. 2000. Constraining the age of Neoproterozoic glaciation in eastern Brazil: First U-Pb SHRIMP data from detrital zircons. Revista Brasileira de Geociências, 30: 58-61.

Pedrosa-Soares, A.C., Noce, C.M., Wiedemann, C.M. \& Pinto, C.P. 2001. The Araçuaí-West Congo orogen in Brazil: An overview of a confined orogen formed during Gondwanland assembly. Precambrian Research, 110: 307-323.

Pedrosa-Soares, A.C., Pinto, C.P., Netto, C., Araujo, M.C., Castañeda, C., Achtschin, A. B. \& Basílio, M.S. 2001. A Província Gemológica Oriental do Brasil. In: C. Castañeda, J.E. Addad \& A. Liccardo (eds), Gemas de Minas Gerais. Belo Horizonte, Sociedade Brasileira de Geologia-Núcleo Minas Gerais, p. 16-33.

Pedrosa-Soares, A.C., Noce, C.M., Alkmim, F.F., Silva, L.C., Cordani, U.G., Marshak, S., Whittington, A., Martins-Neto, M.A. \& Campos, C.M. 2003. Orógeno Confinado: conceito, exemplo e candidatos. In: Simpósio Nacional de Estudos Tectônicos, 9,
Búzios. SBG-RJ, Boletim de Resumos, p. 36-39.

Pedrosa-Soares, A. C., Castañeda, C., Queiroga, G., Gradim, C., Belém, J., Roncato, J., Novo, T., Dias, P., Gradim, D., Medeiros, S., Jacobhson, T., Babinski, M. \& Vieira, V. 2006. Magmatismo e Tectônica do Orógeno Araçuaí no Extremo Leste de Minas Gerais e Norte do Espírito Santo. Geonomos, 14 (2): 97-111.

Pedrosa-Soares, A.C., Alkmim, F.F., Tack, L., Noce, C.M., Babinski, M., Silva, L.C., Martins-Neto, M.A. 2008. Similarities and differences between the Brazilian and African counterparts of the Neoproterozoic Araçuaí-West-Congo orogen. Geological Society, London, Special Publications, 294 (a ser lançado em início de 2008).

Peres, G.G., Alkmim, F.F. \& Jordt-Evangelista, H. 2004. The southern Araçuaí belt and the Dom Silvério Group: Geologic architecture and tectonic significance. Anais Academia Brasileira de Ciências, 76: 771-790.

Pinto, C.P., Drumond, J.B.V., Féboli, W.L. (coord.) 1997. Projeto Leste, Etapa 1. CPRM-COMIG, Belo Horizonte.

Pinto, C.P., Drumond, J.B.V., Féboli, W.L. (coord.) 2001. Projeto Leste, Etapas 1 e 2. CPRM-COMIG, Belo Horizonte, CDROM.

Porada, H. 1989. Pan-African rifting and orogenesis in southern to equatorial Africa and Eastern Brazil. Precambrian Research, 44: 103-136.

Pisarevsky, S.A., Wingate, M.T.D., Powell, C.M., Johnson, S. \& Evans, D.A.D. 2003. Models of Rodinia assembly and fragmentation. Geological Society, London, Special Publications, 206: $35-55$.

Queiroga, G.N., Pedrosa-Soares, A.C., Quéméneur, J. \& Castañeda, C. 2006. A unidade metassedimentar do ofiolito de Ribeirão da Folha, Orógeno Araçuaí, Minas Gerais: petrografia, geotermobarometria e calcografia. Geonomos, 14 (1): 25-35.

Queiroga, G.N., Pedrosa-Soares, A.C., Noce, C.M., Alkmim, F.F., Pimentel, M.M., Dantas, E., Martins, M., Castañeda, C., Suita, M.T.F. \& Prichard, H. 2007. Age of the Ribeirão da Folha ophiolite, Araçuaí Orogen: The U-Pb Zircon (la-icpms) dating of a plagiogranite.

Geonomos, 15 (este número).

Rogers, J.W. \& Santosh, M. 2004. Continents and Supercontinents. Oxford University Press, $289 \mathrm{p}$

Roncato, J., Pedrosa-Soares, A.C., Babinski, M., Jacobsohn, T., Queiroga, G., Castañeda, C., Greco, S. \& Fanning, M. 2007. Heterogeneidade deformacional da Suíte Carlos Chagas (Orógeno Araçuaí) e a idade U-Pb SHRIMP do Giallo Veneziano. In: Simpósio de Geologia do Sudeste, 10, Diamantina. SBGMG, Resumos.

Sampaio, A.R., Martins, A.M., Loureiro, H.C., Arcanjo, J.B., MoraesFilho, J.C., Souza, J.D., Pereira, L.H., Couto, P.A., Santos, R.A., Melo, R.C., Bento, R.V. \& Borges, V.P. 2004. Projeto Extremo Sul da Bahia: Geologia e Recursos Minerais. Salvador, Série Arquivos Abertos da Companhia Bahiana de Pesquisa Mineral, 19, $52 \mathrm{p}$.

Santos, R.F., Alkmim, F.F. \& Pedrosa-Soares, A.C. 2007. A Formação Salinas, Orógeno Araçuaí, MG: História deformacional e significado tectônico. Submetido à Revista Brasileira de Geociências.

Santos, R.V., Alvarenga, C., Babinski, M., Ramos, M., Curkrov, N., Fonseca, M.A., Dardenne, M., Sial, A.N. \& Noce, C.M. 2004. Carbon isotopes of Mesoproterozoic-Neoproterozoic sequences from southern São Francisco craton and Araçuaí Belt: Paleogeographic implications. Journal of South American Earth Sciences, 18: 27-39.

Schobbenhaus, C., Campos, D.A., Derze, G.R. \& Asmus, H.E. 1984. Geologia do Brasil. Brasília, DNPM, 501 p.

Siga-Júnior, O., Teixeira, W.; Cordani, U.G., Kawashita, K. \& Delhal, J. 1982. O padrão geológico-geocronológico das rochas de alto grau da parte setentrional da faixa Ribeira a norte do Rio de Janeiro, Brasil. In: Congresso Latinoamericano Geologia, 5, Argentina. Actas, v. 1, p. 349-370.

Siga-Júnior, O. 1986. A evolução geocronológica da porção nordeste de Minas Gerais, com base em interpretações geocronológicas. São Paulo, IG-USP, Dissertação de Mestrado.

Silva, J.M.R, Lima, M.I.C., Veronese, V.F., Ribeiro Junior, R.N. \& Siga-Júnior, O. 1987. Geologia, Folha SE.24 Rio Doce. Rio de 
Janeiro, IBGE, Projeto Radambrasil, Levantamento de Recursos Naturais, v. 34

Silva, L.C., Armstrong, R, Noce, C.M., Carneiro, M., Pimentel, M., Pedrosa-Soares, A. C., Leite, C., Vieira, V. S., Silva, M., Paes, V. \& Cardoso-Filho, J. 2002. Reavaliação da evolução geológica em terrenos pré-cambrianos brasileiros com base em novos dados U-Pb SHRIMP, parte II: Orógeno Araçuaí, Cinturão Móvel Mineiro e Cráton São Francisco Meridional. Revista Brasileira de Geociências, 32: 513-528.

Silva, L.C., McNaughton, N.J., Armstrong, R., Hartmann, L. \& Fletcher, I. 2005. The Neoproterozoic Mantiqueira Province and its African connections. Precambrian Research, 136: 203-240.

Silva, L.C., Pedrosa-Soares, A.C. \& Teixeira, L.R. 2007. Tonian rift-related, A-type continental plutonism in the Araçuaí orogen, Eastern Brazil: new evidences for the breakup stage of the São Francisco-Congo Paleocontinent. Gondwana Research (no prelo, doi:10.1016/j.gr.2007.06.002)

Silva, L.C., Pinto, C.P., Gomes, A.C.B \& Paes, V. 2007. Geocronologia U-Pb (LA-ICP-MS) e a cronoestratigrafia granítica no segmento NE do Orógeno Araçuaí, MG. In: Simpósio de Geologia do Sudeste, 10, Diamantina. SBG-MG, Resumos.

Söllner, H. S., Lammerer, B. \& Weber-Diefenbach, K. 1991. Die Krustenentwicklung in der Küstenregion nördlich von Rio de Janeiro, Brasilien. Müncher Geologische Hefte, 4: 1-100.

Suita, M.T.F., Pedrosa-Soares, A.C., Leite, C., Nilson, A.A. \& Prichard, H. 2004 Complexos Ofiolíticos do Brasil e a Metalogenia Comparada das Faixas Araçuaí e Brasília. In: E. Pereira, R. Castroviejo \& Ortiz, F. (eds), Complejos Ofiolíticos en Iberoamérica: guías de prospección para metales preciosos. Ciencia y Tecnología para el Desarrollo-CYTED, Madrid, p. 101-132.

Tack, L., Wingate, M.T.D., Liégeois, J.P., Fernandez-Alonso, M. \& Deblond, A. 2001. Early Neoproterozoic magmatism (1000-910 Ma) of the Zadinian and Mayumbian groups (Bas-Congo): Onset of Rodinian rifting at the western edge of the Congo craton. Precambrian Research, 110: 277-306.

Torquato, J.R. \& Cordani, U.G. 1981. Brazil-Africa geological links. Earth Science Reviews, 17:155-176.

Trompette, R. 1994. Geology of Western Gondwana (2000-500 Ma). Pan-African-Brasiliano aggregation of South America and Africa. Rotterdam, A.A. Balkema, 350 p.

Uhlein, A. 1991. Transição craton-faixa dobrada: um exemplo do Cráton do São Francisco e da Faixa Araçuai (Ciclo Brasiliano) no Estado de Minas Gerais: Aspectos estratigráficos e estruturais. São Paulo, IG-USP, Tese de Doutorado.

Uhlein, A., Trompette, R. \& Egydio-Silva, M. 1998. Proterozoic rifting and closure, SE border of the São Francisco craton, Brazil. Journal of South American Earth Sciences, 11: 191-203.

Uhlein, A., Trompette R. \& Alvarenga, C. 1999. Neoproterozoic glacial and gravitational sedimentation on a continental rifted margin: The Jequitaí-Macaúbas sequence (Minas Gerais, Brazil). Journal of South American Earth Sciences, 12: 435-451.

Uhlein, A., Trompette, R., Egydio-Silva, M. \& Vauchez, A. 2007. A Glaciação Sturtiana ( $750 \mathrm{Ma})$, a Estrutura do Rifte MacaúbasSanto Onofre e a Estratigrafia do Grupo Macaúbas, Faixa Araçuaí. Geonomos, 15 (este número).

Vauchez, A., Egydio-Silva, M., Babinski, M., Tommasi, A., Uhlein, A. \& Liu, D. 2007. Deformation of a pervasively molten middle crust: insights from the Neoproterozoic Ribeira-Araçuaí orogen (SE Brazil). Terra Nova, 19: 278-286.

Vieira, V.S. 2007. Significado do Grupo Rio Doce no Contexto do Orógeno Araçuaí. Belo Horizonte, IGC-UFMG, Tese de Doutorado.

Vieira, V.S., Pedrosa-Soares, A.C. \& Silva, L.C. 2007. Significado do Grupo Rio Doce no Contexto do Orógeno Araçuaí. In: Simpósio de Geologia do Sudeste, 10, Diamantina. SBG-MG, Resumos.

Viveiros, J.F.M., Sá, E.L., Vilela, O.V., Santos, O.M., Moreira, J.M.P., Holder-Neto, F. \& Vieiea, V.S. 1978. Geologia dos vales dos rios Peixe Bravo e Alto Vacaria, norte de Minas Gerais. In: Congresso Brasileiro de Geologia, 30, Recife. SBG, Anais, v. 1, p. 243-254.

Whittington A.G., Connelly J., Pedrosa-Soares A.C., Marshak S. \& Alkmim F.F. 2001. Collapse and melting in a confined orogenic belt: Preliminary results from the Neoproterozoic Araçuaí belt of eastern Brazil. In: American Geophysical Union Meeting, 2001, San Francisco. Abstract T32B-0895, v. 82, p.1181-1182.

Wiedemann C.M. 1993. The evolution of the Early Paleozoic, late- to post-collisional magmatic arc of the coastal mobile belt, in the State of Espírito Santo, eastern Brazil, Anais Academia Brasileira Ciências, 65: 163-181.

Wiedemann-Leonardos, C.M., Ludka, I.P., Medeiros, S.R., Mendes, J.C. \& Moura, J.C. 2000. Arquitetura de plútons zonados da Faixa Araçuaí-Ribeira. Geonomos, 8: 25-38.

Wiedemann, C.M., Campos, C.M., Medeiros, S.R., Mendes, J.C., Ludka, I.P. \& Moura, J.C. 2002. Architecture of Late orogenic Plutons in the Araçuaí-Ribeira Folded Belt, Southeast Brazil. Gondwana Research, 19: 381-399. 